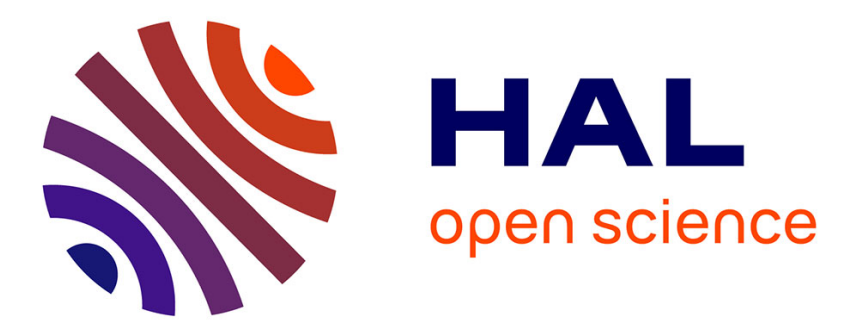

\title{
Coastal flooding event definition based on damages: Case study of Biarritz Grande Plage on the French Basque coast
}

Florian Arnoux, Stéphane Abadie, Xavier Bertin, Ivan Kojadinovic

\section{To cite this version:}

Florian Arnoux, Stéphane Abadie, Xavier Bertin, Ivan Kojadinovic. Coastal flooding event definition based on damages: Case study of Biarritz Grande Plage on the French Basque coast. Coastal Engineering, 2021, 166, pp.103873. 10.1016/j.coastaleng.2021.103873 . hal-03200009

HAL Id: hal-03200009 https: / hal-univ-pau.archives-ouvertes.fr/hal-03200009

Submitted on 16 Apr 2021

HAL is a multi-disciplinary open access archive for the deposit and dissemination of scientific research documents, whether they are published or not. The documents may come from teaching and research institutions in France or abroad, or from public or private research centers.
L'archive ouverte pluridisciplinaire HAL, est destinée au dépôt et à la diffusion de documents scientifiques de niveau recherche, publiés ou non, émanant des établissements d'enseignement et de recherche français ou étrangers, des laboratoires publics ou privés.

\section{(ㅇ)(1) $\$$}

Distributed under a Creative Commons Attribution - NonCommercial - NoDerivatives| 4.0 


\title{
Coastal flooding event definition based on damages: Case study of Biarritz Grande Plage on the French Basque coast
}

\author{
Florian Arnoux ${ }^{1,2 *}$, Stéphane Abadie ${ }^{1}$, Xavier Bertin $^{3}$, Ivan Kojadinovic ${ }^{2}$
}

\begin{abstract}
This paper presents a method to include damage at the initial stage of coastal flooding events definition and in return periods computation. The methodology is illustrated within a local study carried out in Biarritz Grande Plage, a meso-tidal, wave dominated beach located on the french basque coast in the south west of France. The work is based on two datasets covering the period 1949-2015 : a first one, consisting of observation and synthetic data on wave characteristics and water level, and a second one, gathering storm dates and related damage intensities obtained through investigations in the press and in archives. A statistical analysis was first carried out to find the best combination of source variables explaining the reported damages for the identified storms. Maximal, mean and accumulated values were calculated over storm duration, considering source and aggregated variables based on the empirical run-up formula or the wave energy flux. Most rules combining a wave parameter and water level are found to provide satisfactory damage prediction as soon as maxima variables are considered. Rules based on mean variables are less accurate and those based on accumulated variable values are not relevant. The best results are obtained with the wave energy flux and water level maxima over the storm duration. The ability of the rules to be used as generic event definition rules is then tested by performing a retrospective analysis on the whole dataset, checking their efficiency in detecting historical storms (i.e., with damages) without finding too many false positives. Most of the rules formerly studied, except the ones using wave period only as wave parameter, were able to correctly perform this task. Coastal flood event return periods (RP) were then calculated by applying three of the best rules identified previously. The rule using non simultaneous maxima of wave energy flux and water level gives encouraging results for the RP values. Nevertheless, the discrepancy still observed among the different rules calls for further work in this direction.
\end{abstract}

Keywords

coastal flooding ; return period ; storm ; event definition ; damage ; historical data ; risk ; Basque coast

1 Université de Pau et des Pays de l'Adour, E2S UPPA, SIAME, Anglet, France

${ }^{2}$ Université de Pau et des Pays de l'Adour, E2S UPPA, LMAP, Pau, France

${ }^{3}$ UMR LIENS, La Rochelle, France

*Corresponding author: florian.arnoux@univ-pau.fr

\section{Introduction}

Mitigating coastal flooding is a common concern of countries with maritime borders. Whereas the problem is more and more acute due to the growing coastal population and associated infrastructures [1], climate change also increases pressure on the coast by sea level rise which allows the ocean to reach usually protected areas [2]. Nations cope with this problem by developing coastal flood management plans, for which, one important task is the identification of coastal zones at flooding risk [3]. The objective is usually to delineate a flooding line associated with a given return period (RP). If the methodologies developed over the years to build these risk maps may differ from one nation to the other, the processes that have to be taken into account are generally common, even though some process may be predominant in one location compared to the other. In this framework, common flooding processes include water level variations due to sea level rise, tides, surge and wave set-up as well as to higher frequency processes such as run-up due to infragravity and incident waves and/or overtopping.

The definition of coastal flood return period (RP) is intimately related to the notion of event as described in [4], [5] and [6]. As explained in theses papers, RP calculation should first apply a physical declustering on the initial autocorrelated time series of observations in order to obtain an independent and identically distributed (i.i.d.) sample of an event-describing random variable. The second step consists of determining the statistical threshold above which the exceedances of the event-describing variable may be modelled by a suitable statistical distribution, usually the Generalized 
Pareto Distribution (GPD). The physical declustering step is crucial as it will totally define the meaning and the value of the RP calculated. It should therefore be adapted to the studied phenomenon and to the end-users of the study.

At this stage an important distinction has to be made between source, response variables and impacts. A given storm is characterized by source variables such as waves, water level, wind, atmospheric pressure and induces various responses at the coast such as flooding, overtopping, wave loading, in turn resulting into various impacts (erosion, damages on infrastructures, fatalities). Note that erosion can be seen as a response variable as well as an impact.

Various declustering methods can be found in the literature. They differ depending on the impact and the number of source variables considered and the way the source variables are processed. For instance, [7], studying erosion as impact, based the definition of the events on a wave height exceedance criterion, the events thus defined, being then complemented with other variables such as wave covariates and water level reduced to the surge component. In this case, the event is defined through a threshold on a unique source variable. But source variables can also be combined to form a structural variable or response variable. For instance, [5] applied a declustering procedure to a response function built by summing the sea level to the nearshore wave height. Total water level including run-up and set-up is also often used [8]. A multivariate threshold can also drive the declustering procedure. [9] used a bivariate threshold in which an event is defined when both the significant wave height and the meteorological surge exceed given values.

As formerly stressed, the value and meaning of the RP may be highly sensitive to the event definition procedure which should, therefore, be related to the impact it is supposed to characterize. Stakeholders being mostly concerned by the impacts to the coast and population, RP should reflect this aspect in applied studies. The literature nevertheless shows that the link between the event definition procedure and the impact (i.e., erosion, infrastructure damages, etc.) is often vague or based on general considerations. Nevertheless, this question must be in some way addressed in order to better justify crucial choices usually made in the event definition procedure as the combination or characteristics (i.e., peak value, integral value, etc. ) of source variables.

In that context, historical data can help better understanding the complex relationship between source variables and impact. The interest on historical data in the coastal flooding has been acknowledged mostly in the last ten years even though few older references exists [10]. The multiple very recent references show the growing interest of the community for using historical data in coastal risk prevention. As examples, [11] combined historical data with numerical hindcast to investigate the recurrence of major flooding in the central part of the Bay of Biscay; [12] presents a database on 329 coastal flooding events reported in the period 1915-2016 and ranked using a multi-level categorisation; [13] proposes a historical analysis of the occurrence of storms and their damage intensity from The Middle Ages to the 1960s at several study sites along the European coasts; [14] gathered and used extensive historical data at the site of Dunkirk (France) to quantify extreme sea levels and skew surges, and [15] joined historical, statistical and modeling approaches to characterize past flooding events at the city of Gâvres in France. Note that a french Working Group named "Tempetes et Submersion Marines" and led by the Institut de Radioprotection et de Sûreté Nucléaire (IRSN) has recently built a database of historical storms in France, with a qualification of both the sources and the damages [16].

This paper is an attempt to include impact in the procedure of coastal flooding event definition. The idea developed is to test several rules based on the source variables to explain damages reported in a historical dataset. Based on the selected optimized rules, RPs are finally computed in order to illustrate the sensitivity of the rules with respect to the variables they involve. This methodology is applied to a local site study, Biarritz on the Basque coast (SW of France), for which historical and oceanographical datasets have been constructed.

The structure of the article is as follows :

- In section 2, the damage, wave and water level databases are first described. Then, the candidate damage rules, involving source and structural variables, are presented as well as the associated processing (i.e., calculation of maximum value, mean value, etc.).

- In section 3, the different rules are tested against the damage historical data and the best ones are retained. A validation stage consists then of verifying the ability of the rules to not generate false positives when blind running. Subsequently, return periods of historical storm events are calculated using the damage rules obtained previously.

- Finally, results are discussed in section 4.

\section{Material and methods}

\subsection{Site description}

The Basque coast (Fig. 1) is a $200 \mathrm{~km}$ rocky coast facing the Atlantic Ocean and stretching from the north of Spain to the south west of France. In this paper, we specifically focused on one site : the so-called Biarritz "Grande Plage" (Fig. 2), a touristic seaside resort where hotels, casino, infrastructures are often damaged by storms. The area is indeed submitted to a highly energetic wave climate. A wave buoy installed since 2009 off Biarritz in $50 \mathrm{~m}$ depth allows to assess this climate. Statistics computed from 9 years data available on the Candhis internet web site (http: / / candhis . cetmef.developpement-durable.gouv.fr) show that the wave incidence is almost completely restricted to the west-north west and north west angular sector. Extreme events can be illustrated by wave height return periods. The data shows that the significant wave height 10 -year return period 
at this particular location lies between 8.43 and $9.63 \mathrm{~m}$ with a $70 \%$ confidence percentage. For these sea states, the expected peak period is about $16 \mathrm{~s}$. The Grande Plage beach is a mesotidal beach with $4.5 \mathrm{~m}$ spring tidal range around a mean water level of $2.64 \mathrm{~m}$ (Charts datum). Due to the bathymetry in this area, in which deep water is relatively close to the shore, storm winds do not generally account significantly to surges, which are completely driven by atmospheric pressure variations. The Grande Plage beach is an intermediate-reflective beach with a mean sediment grain diameter equal to $0.3 \mathrm{~mm}$ and typically exhibiting a steep foreshore slope of $8-9 \%$ and a gentle nearshore slope of $2-3 \%$ [17]. Finally, the water front is composed of a waterfront boardwalk (Figure 2 right) located at $7.65 \mathrm{~m} \mathrm{CD}$.

\subsection{Dataset}

\subsubsection{Damage database}

A database reporting flooding events and associated damages was collected at the French Basque coast scale by a research in archives for the period 1950-2014 [18, 19, 20]. The main source of data comes from systematic investigations in the national and local press, and in particular in the regional newspaper Sud-Ouest, as well as in the public archives kept by the government representatives, public bodies and local authorities. The methodology, see [20] for a detailed description, was inspired by the French project COCORISCO (http: / / www.risques-cotiers.fr/ $\mathrm{fr}$ /projets/cocorisco) on coastal risks and built on previous experiences research and mapping of historical archives on disasters conducted by part of the team. An assessment of the probability of flooding and associated damage was carried out. As already mentioned, in this paper we focus on the Grande Plage in Biarritz, for which the most continuous series of information has been collected. We tried to find some evidences of flooding or non-flooding, the term flooding referring to the flooding of the waterfront boardwalk (Fig. 2). The events that have supposedly caused flooding at the Grande Plage were marked by an index of 1 and 0 in case of no flooding. A confidence index (1: reliable, 0: low reliability) has been added to this information for more relevant statistical processing. The same analysis was carried out for the intensity of the damage. A three-level scale (2 for significant damage, 1 for moderate damage and 0 for zero damage) was chosen as the most appropriate, taking into account the accuracy of the information found. A confidence index on this value has also been added for further processing.

The difference between level 2 and level 1 damage events was made by analyzing the historical documents and trying to find explicit proofs of the damage extent. The level 2 category is characterized by significant damages evidences (photographs, repair quotations, etc.) to the buildings and especially to the glass windows of the casino or the hotels lying along the waterfront. Events were classified as level 1 when light damages are reported, for instance public bench broken, light damages on the road or the seawall but not on the buildings. Finally, note that waves and water level data (see section 2.2.2) were used a posteriori in order to eliminate storm events from the damage database (Table 1), for which damages were likely not caused by flooding (i.e., rather by wind or rain). For this, the values of the empirical cumulative distribution function (cdf) (see equation 4 for the definition) for wave height, water level and run-up were computed over the event period when there was a doubt on the origin of the damages. This concerns only a few cases as for several others, the flooding is obvious from photographs. The examination of the cdf values is efficient in discriminating the event as most of the events exhibits very high cdf values close to the maximum (typically around 0.99 ) except a few ones, for which cdf values are only average. The latter were removed from the database. Note that this method may not be totally justified for sites involving coastal defences. Indeed, in this case, the failure of a critical structure during an event may lead to damages even for moderately energetic conditions [15]. Nevertheless, as La Grande Plage faces the main energetic wave directions without any intermediate protective structures, the procedure described is relevant.

The Biarritz Grande Plage database is summarized in Table 1. Information indicating whether or not the event was classified as a natural disaster (i.e., CATNAT statement) are also added to complete this database.

The number of storms, for which only Biarritz was mentioned is 30 and the number of flood events at the Grande Plage is 13, which represents one third of the storms observed over the period 1950-2014. Of these flooding events, only 2 are considered as unreliable. With regard to non-flooding events, the information is most often considered unreliable. In 2 events only, flooding is excluded with confidence. With regard to damages, 5 events generated a level damage 2 with good reliability and 4 caused moderate damage with only one assessment considered unreliable in this category. The remaining storms did not cause any damage with a good level of confidence. The storms that caused the main damage (level 2) due to flooding are the storms of December 28-29 1951, November 9-10 2010 and the recent events of the winter of 2013-2014 including the so-called Hercules (January 4-7), Nadja (February 1-2) and Christine (March 3-5) storms.

In the present paper, only the information on damages was finally used in the analysis. Indeed, the additional information on the occurrence of flooding and the associated confidence level, is rather scarce due to the low confidence level associated to this information (only 5 new events are associated to good confidence : 3 flooding and 2 no flooding events). In particular there are not enough trusted storm events with no flooding to allow defining a clear separation between flooding and no flooding events.

\subsubsection{Wave and water level data}

In addition to the former damage database, a corresponding hazard database composed of wave and water level data and covering the same period was also established [21]. Water level data was built from tide gauge observations collected at 


\begin{tabular}{|c|c|c|c|c|c|c|c|c|}
\hline $\begin{array}{c}\text { Storm } \\
\text { name }\end{array}$ & $\begin{array}{l}\text { Start } \\
\text { date }\end{array}$ & $\begin{array}{l}\text { End } \\
\text { date }\end{array}$ & $\begin{array}{c}\text { Duration } \\
\text { (days) }\end{array}$ & $\begin{array}{l}\text { Flooding } \\
\text { occurrence }\end{array}$ & confidence & $\begin{array}{l}\text { Damage } \\
\text { intensity }\end{array}$ & confidence & CATNAT recognition \\
\hline 1 & $12 / 28 / 1951$ & $12 / 30 / 1951$ & 2 & 1 & 1 & 2 & 1 & NA \\
\hline 2 & $14 / 12 / 1958$ & $15 / 12 / 1958$ & 1 & 0 & 0 & 0 & 1 & NA \\
\hline 3 & $12 / 11 / 1961$ & $14 / 11 / 1961$ & 2 & 0 & 0 & 0 & 1 & NA \\
\hline 4 & $17 / 01 / 1965$ & $20 / 01 / 1965$ & 3 & 1 & 1 & 1 & 1 & NA \\
\hline 5 & $30 / 10 / 1967$ & $05 / 11 / 1967$ & 6 & 1 & 1 & 1 & 0 & NA \\
\hline 6 & $11 / 12 / 1968$ & $17 / 12 / 1968$ & 6 & 1 & 1 & 0 & 0 & NA \\
\hline 7 & $20 / 01 / 1972$ & $22 / 01 / 1972$ & 2 & 1 & 0 & 0 & 1 & NA \\
\hline 8 & $06 / 02 / 1974$ & $08 / 02 / 1974$ & 2 & 1 & 0 & 0 & 1 & NA \\
\hline 9 & $24 / 01 / 1984$ & $25 / 01 / 1984$ & 1 & 0 & 0 & 0 & 1 & NO \\
\hline 10 & $30 / 01 / 1988$ & $01 / 02 / 1988$ & 2 & 0 & 0 & 0 & 1 & NO \\
\hline 11 & $25 / 02 / 1989$ & $27 / 02 / 1989$ & 2 & 0 & 0 & 0 & 1 & NO \\
\hline 12 & $30 / 01 / 1990$ & $01 / 02 / 1990$ & 2 & 1 & 1 & 1 & 1 & $30 / 1 / 1990$ \\
\hline 13 & $07 / 02 / 1996$ & $09 / 02 / 1996$ & 2 & 0 & 0 & 0 & 1 & NO \\
\hline 14 & $28 / 12 / 1998$ & $02 / 01 / 1999$ & 5 & 1 & 1 & 1 & 1 & $\mathrm{NO}$ \\
\hline Martin & 27/12/1999 & $31 / 12 / 1999$ & 4 & 0 & 1 & 0 & 1 & $25-29 / 12 / 1999$ \\
\hline 16 & $06 / 11 / 2000$ & $10 / 11 / 2000$ & 4 & 0 & 0 & 0 & 1 & NO \\
\hline 17 & $07 / 12 / 2000$ & $09 / 12 / 2000$ & 2 & 0 & 1 & 0 & 1 & NO \\
\hline 18 & $14 / 08 / 2008$ & $16 / 08 / 2008$ & 2 & 0 & 0 & 0 & 1 & NO \\
\hline Klaus & $23 / 01 / 2009$ & $25 / 01 / 2009$ & 2 & 0 & 0 & 0 & 1 & $24-27 / 1 / 2009$ \\
\hline 20 & $09 / 11 / 2010$ & $11 / 11 / 2010$ & 2 & 1 & 1 & 2 & 1 & $8-10 / 11 / 2010$ \\
\hline Quirin & $15 / 02 / 2011$ & $17 / 02 / 2011$ & 2 & 0 & 0 & 0 & 1 & NO \\
\hline 22 & $18 / 02 / 2011$ & $23 / 02 / 2011$ & 5 & 1 & 1 & 0 & 1 & NO \\
\hline 23 & $13 / 12 / 2011$ & $18 / 12 / 2011$ & 5 & 0 & 0 & 0 & 1 & NO \\
\hline 24 & $26 / 01 / 2013$ & $31 / 01 / 2013$ & 5 & 0 & 1 & 0 & 1 & NO \\
\hline 25 & $09 / 02 / 2013$ & $14 / 02 / 2013$ & 5 & 0 & 0 & 0 & 1 & NO \\
\hline Dirk & $23 / 12 / 2013$ & $26 / 12 / 2013$ & 3 & 0 & 0 & 0 & 1 & NO \\
\hline Hercules & $04 / 01 / 2014$ & $08 / 01 / 2014$ & 4 & 1 & 1 & 2 & 1 & $6-7 / 1 / 2014$ (recognized after trial) \\
\hline Nadja & $01 / 02 / 2014$ & $03 / 02 / 2014$ & 2 & 1 & 1 & 2 & 1 & $2 / 2 / 2014$ \\
\hline Andrea & $26 / 02 / 2014$ & $03 / 03 / 2014$ & 5 & 0 & 0 & 0 & 1 & NO \\
\hline Christine & $03 / 03 / 2014$ & $06 / 03 / 2014$ & 3 & 1 & 1 & 2 & 1 & $4 / 3 / 2014$ \\
\hline
\end{tabular}

Table 1. Database of damages related to coastal flooding in the Biarritz Grande Plage. When the events correspond to known storms, their name is used if not their number. The dates and durations are either extracted or inferred from the press and archives. The Confidence indices are coded as 1 (confident) or 0 (not confident). Damage is coded in intensity 0 (weak/absent), 1 (moderate) or 2 (strong) and flooding occurrence is coded by 1 (presence) and 0 (absence). The last column indicates the storms recognized as CATNAT and the corresponding dates. The state of natural disaster (natural catastrophe $=$ CATNAT) is a situation whose recognition in France by the Ministry of the Interior allows for the systematic compensation of victims of damage caused by various natural agents. This procedure was established in 1982. 

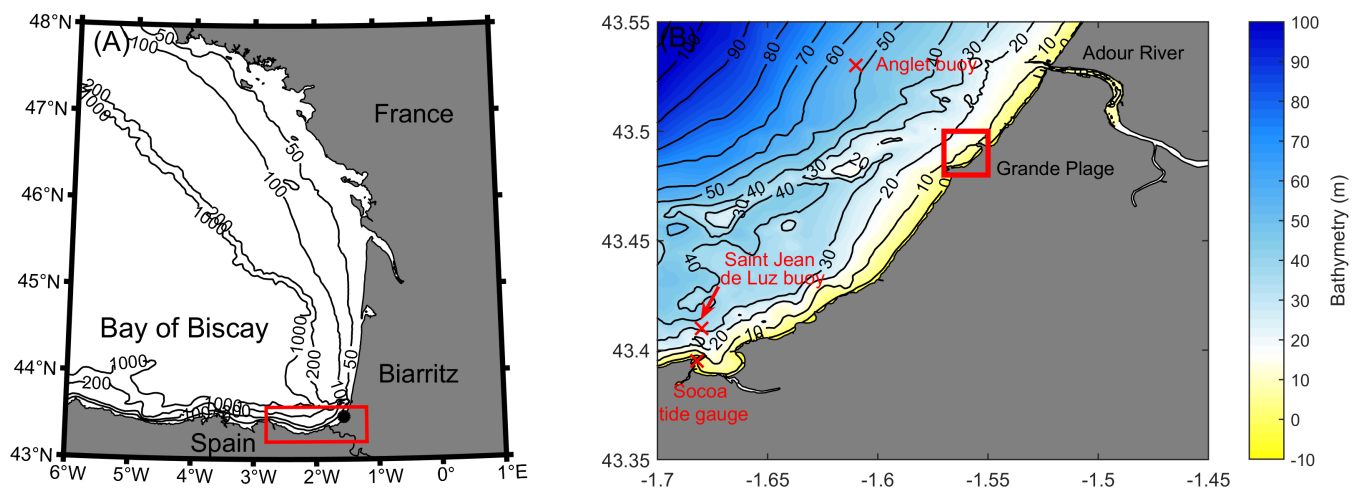

Figure 1. Location of the study site on the France map (left panel) with a zoom on the Basque coast (right panel - red rectangle) with buoys (Anglet and Saint-Jean-de-Luz) and tide gauges (Socoa) used on this study.
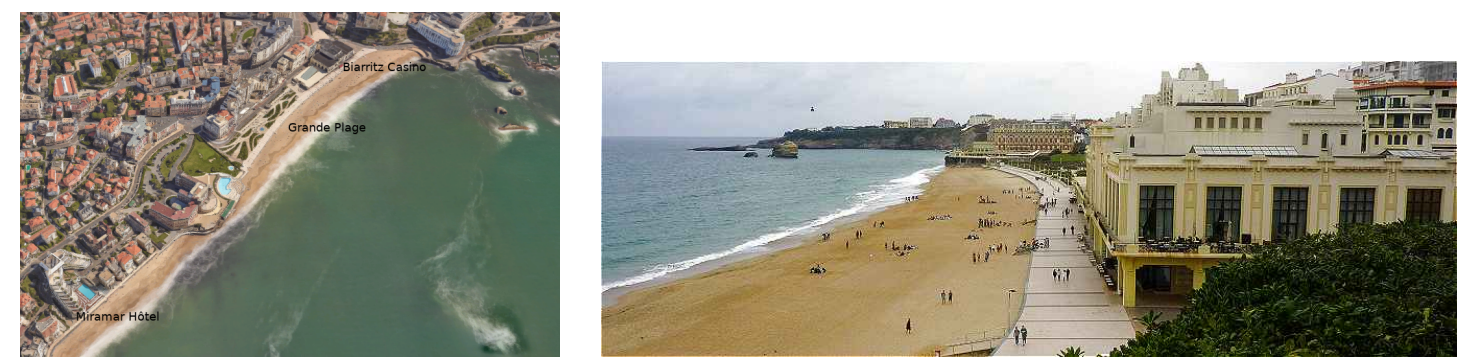

Figure 2. Photographs of the Grande Plage of Biarritz showing a few of the assets frequently flooded (left panel - CGoogle Maps), the Grande Plage waterfront and the the casino building (right panel - CFranceBallade)

Socoa (40 km the South of Biarritz). This station has been collected data since 1942. A tide gauge located in Boucau in the Adour rivermouth (5-10 km north of Biarritz) is also collecting data since 1967 but this gauge was finally not considered due to assumed high influence of the river flow. This choice is also justified by the spatially homogeneity of the water level at this scale as evidenced by data comparison on overlapping period. At the Socoa tide gauge, the fraction of missing data being quite significant (43\%), a synthetic reconstruction of the signal has been carried out. The model used to that purpose is the sum of three components : the average water level at time $t$, which is a moving average calculated from the monthly averages of the measurements, the tidal signal at time $t$, calculated by harmonic analysis of the tide gauge observations, and a rough estimate of a surge component at time t, obtained from atmospheric pressure simulation data. This rather simple model seems sufficient [21] to obtain consistent series of water level values for the period 1949-2015 (RMSE $=0.08 \mathrm{~m}$, $\mathrm{R} 2=0.99$, Bias $=0.0 \mathrm{~m}$ obtained comparing data and model).

Wave observations are spatially and temporally limited. Two wave buoys are currently collecting data nearby Biarritz coast (50km radius) : one buoy off Saint Jean de Luz since 2013 (20 m water depth) and one off Biarritz coast since 2009 (50 m water depth), already mentioned in section 2.1. Additionally, non directional wave measurements were also performed from 1989 to 1994 off the entrance of the Adour Rivermouth in $20 \mathrm{~m}$ water depth. Unfortunately, these mea- surements cover a too short period to be used for the statistical study. For this reason, the wave dataset is composed of hindcast wave data whose quality was assessed in comparison with the aforementioned measured data. The main hindcast simulation, hereafter referred to as WWMII, covers the study period (1949 à 2015). It was carried out using a modeling system that couples the 2DH circulation model based on SELFE [22] and the spectral model WWMII for waves [23]. The configuration described in [24] has been implemented throughout the North Atlantic Ocean, with a spatial resolution of a few tens of $\mathrm{km}$ in the deep ocean to $1 \mathrm{~km}$ along the coast of the Bay of Biscay. This model was forced with $10 \mathrm{~m}$ wind and sea-level pressure from NCEP/NCAR reanalysis [25], thus ensuring a good temporal homogeneity over the period studied.

The model gives access to the integrated wave parameters (i.e., significant height $H_{m 0}$, peak period $T_{p}$, etc.) at several points corresponding to the wave measurements performed all along the Basque coast and in front of the main coastal cities (at $-100 \mathrm{~m}$ and $-15 \mathrm{~m}$ depth). In this study, only the point located at the Biarritz wave buoy is used.

WWMII data were compared with the directional wave buoy measurements located $6 \mathrm{~km}$ off Biarritz in [21]. This comparison shows an RMSE error of $48 \mathrm{~cm}$, a determination coefficient R2 of 0.73 and a bias of $6.98 \mathrm{~cm}$ on the wave height. The analysis of quantile/quantile graphs shows an underestimation by the model for extreme sea states, detrimental to this type of study precisely focused on these events. In [21], 
the in situ data from the wave buoy is used to perform an empirical quantitative correction of the simulated data. For a given variable, this operation leads to a simulated time series with the same distribution that the buoy time series. It is this last corrected data that is considered in this work.

Finally, note that comparisons were also performed with the HOMERE database obtained from the spectral model WAVEWATCH III but spanning a shorter temporal period and an unstructured grid covering the Bay of Biscay [21] and this latter dataset also shows the same trend to underestimate large wave height values.

\subsection{Source and structural variables}

Several variables can be used to build the damage function. First, the so-called source or primitive variables, namely wave statistical parameters $\left(H_{s}, T_{m 10}, T_{p}, \theta_{p}\right)$ and water level $\eta$, can be used to explain damages. Therefore, they can be tested directly alone or in combination.

Structural or response variables can also be computed to explain damages. They are generally made up of a combination of source variables and potentially some site-specific characteristics such as the beach slope for instance. Here we tested the wave energy flux $P$, the run-up $R_{2} \%$ (exceeded by $2 \%$ of the waves in a sea states) and the response function $H_{s}+\eta$ defined in [5]. These structural variables are computed for a given sea state represented by the time $t$ (i.e., one $\mathrm{t}$ for one sea state) in the following.

The average wave energy flux or wave power $P\left(J \cdot m^{-1} \cdot s^{-1}\right)$ at a given location for a particular sea state at time $t$ is calculated as:

$$
P=E C_{g}
$$

in which $E\left(J . m^{-2}\right)$, wave energy density given by $E=\frac{1}{16} \rho g H_{s}^{2}$, ( $\rho$ sea water density and $g$ gravity) and $C_{g}$ group velocity given by $C_{g}=\frac{1}{2} C_{p}\left(1+\frac{4 \pi h}{\lambda} \frac{1}{\sinh \left(\frac{4 \pi h}{\lambda}\right)}\right)$ with $h$ local water depth. This group velocity involves the calculation of the phase velocity $C_{p}=\sqrt{\frac{g \lambda}{2 \pi} \tanh \left(\frac{2 \pi h}{\lambda}\right)}$ and a wavelength $\lambda(t)$ solution of the following implicit equation $\left(\frac{2 \pi}{T_{m 10}}\right)^{2}=\frac{2 \pi g}{\lambda} \tanh \left(\frac{2 \pi h}{\lambda}\right)$.

For the run-up computation, we relied on the empirical formulation proposed by [26] :

$$
R_{2 \%}=R_{V}+R_{i n c}+R_{I G}
$$

in which :

- $R_{v}=0.35 \sqrt{H_{s} \frac{g T_{p}^{2}}{2 \pi}} \beta$ : the setup part

- $R_{\text {inc }}=0.75 \sqrt{H_{s} \frac{g T_{p}^{2}}{2 \pi}} \beta:$ the incident part of the swash

- $R_{I G}=0.06 \sqrt{H_{s} \frac{g T_{p}^{2}}{2 \pi}}:$ the infra gravitational part of the swash

Each coefficient was estimated based on field data obtained on different beaches. The calculations require the slope $\beta$ (i.e. the tangent of the angle) of the considered beach which is obviously not constant in the present study. In this work, an average value of 0.09 is considered based on measurements performed between 2017-2019 [27].

Finally, we obtain a large matrix with raw geophysical variables $\left(H_{s}, T_{p} \ldots\right)$, structural variables $\left(P, R_{2} \%, H_{s}+\eta\right)$ and water level $\eta$ corresponding to the nearest tide gauge and the sample time covering the period 1949-2015.

\subsection{Data processing}

Data processing is performed using $\mathrm{R}$, the free software environment for statistical computing and graphics [28]. Wave data are sampled every three hours while water level data are known every hour. The first operation is to merge the two data sets. This is done by interpolating wave data on the water level time step (i.e., $1 \mathrm{H})$. Tests were also performed with the $3 \mathrm{H}$ time step (i.e., considering water level only when wave data are known) and the results were very similar. This operation leads roughly to a matrix of 580000 dates.

Then, a first physical sampling is carried out by extracting a subset of this time series composed of data at local maxima of the water level $\eta$ (approximated with a maximum error of $30 \mathrm{~min}$. in time due to the time sampling used). This reduction brings to a dataset of 48000 dates. Therefore, we implicitly assume that the loss of information at lower tide levels is not significant as far as damage is concerned. This is justified for the Basque coast area, including Biarritz, for which the tidal driven water level is always predominant compared to surge water level variation. This common declustering procedure is for instance used in [29] and discussed in [5]. It is usually followed by a Peak Over Threshold (POT) or Block Maxima (BM) approach.

In the present study, the procedure is different. Hypothesis have to be made to design the event definition rule (see Figure 3) :

- In the first one, we assume that damages are generated rather on a short time scale when storm parameters (waves, water level) reach extreme values. To characterize this effect, we rely on variable maxima over a time window. The procedure is simple for one variable. In case two variables, say $\boldsymbol{v}_{1}$ and $\boldsymbol{v}_{2}$, are used in conjunction to explain damages, then a specific procedure has to be applied. In that case, we used three approaches. The first one is to select the actual maximum of each variable over the time window (orange dots in Figure 3). In this case, the two maxima are usually reached at different times. The second one is to select the maximum for one variable and take the value of the other variable at the same time (green dots in Figure 3). The last one is to calculate the date for which the two variables take simultaneously a value close to their maxima (red dots in Figure 3). This is performed using the product of the 
two cdf as follows :

$$
I(t)=\hat{F}_{N}^{1}\left(v_{1}(t)\right) \times \hat{F}_{N}^{2}\left(v_{2}(t)\right) .
$$

In which, the cdf for a given variable $v$ is defined as :

$$
\hat{F}_{N}^{v}(x)=\frac{1}{N} \sum_{i=1}^{N} \mathbf{1}\left(v_{i} \leq x\right), \quad x \in \mathbb{R},
$$

with $N$ is the size of the dataset considered (here roughly $48000)$ and $\mathbf{1}\left(v_{i} \leq x\right)$ the indicator function which values 1 if the value $v_{i}$ is above $x$ and 0 if not.

Hence, in equation 3 , the closer $\boldsymbol{v}_{1}$ and $\boldsymbol{v}_{2}$ are to their respective maxima, the closer $I_{t}$ is to one.

- In the second hypothesis, damages are rather explained by a cumulative effect of several successive destructive high tide events. To test this hypothesis mean and sum of variables over several successive high tides are also computed.

Maximum, mean and cumulative variables (source and structural) are computed for the 30 storms identified in the Biarritz damage data base (using start and end dates from columns 2 and 3 in Table 1 as time window for the different computations).

The objective is then to determine the rules explaining the best the observed damages. For this task, we first tested Classification and Regression Trees (CART) algorithms as described by Reiman [30]. In CART, the procedure starts with a learning phase where the best way to classify storms is determined using hazard variables according to the target variable (here the damages indices from the Table 1). Nevertheless, taking into account the relatively small amount of observed storms, the decision tree did not provide better results than through a simple visual interpretation of the different plots generated which is the procedure finally followed in this paper.

\subsection{Validation}

After determining damage rules according to Table 1, we need to test these on the whole wave and water level data set. A good damage rule is supposed to detect a high percentage of the historical events while avoiding false positives. We propose two methods for the validation of the rules.

\subsubsection{Method 1 : direct rule application}

In this method, we distinguish two cases :

1. the damage rule only requires a calculation at one date $t$,

2. the damage rule requires a calculation over the storm duration
In the first case, we will only need to test every date in the dataset and verify if the corresponding threshold(s) is/are exceeded by the values of the considered variables at that date.

In the second case, we process the dataset using a sliding time windows of duration $\tau \geq 0$ anterior to date $t$ considered to compute maxima and means of a considered variable. This time window, depending on the value of $\tau$, includes variable number of dates (i.e. tide cycles). Consecutive time windows have to overlap each other (i.e., the time window is shifted every tide cycle) to avoid missing non simultaneous maxima from the same event.

The validation procedure of this method is summarized in Figure 4. Since, after applying a rule (step 1 : rule application), it is possible for an event to contain more than one date meeting a rule criterion, consecutive dates are grouped into a cluster counting as only one event for the validation (step 2 : cleansing). The time lapse fixed to consider clusters as independent is equal to three tidal cycles (i.e., $36 \mathrm{H}$ ). The final step (sorting) is the distinction between historical events from the data (i.e., damage level 1 and 2 from Table 1) with false positives ( 0 from Table 1 and non identified dates).

\subsubsection{Method 2 : preliminary event detection}

In this method, an event threshold $u_{e}$ (or several depending on the rule function - see definition hereafter) is first applied to the time series (Figure 5). $u_{e}$ must be high enough to create independent clusters but low enough to include the important events. The value of $u_{e}$ must therefore be adapted to the data studied. The subset obtained is then formed of clusters, each including several values for the parameters corresponding to the rule tested. The time laps fixed here to consider clusters as separated is the same as in method 1 (i.e. $36 \mathrm{H}$ ). The next step is to select one value (or set of values) by cluster directly based on the rule considered. This is performed by applying the function of the corresponding rule on the specified time information. A rule is indeed defined with 3 parameters :

1. the function to be applied,

2. a time information (i.e. function to be applied at time $\mathrm{t}$ or over a time window),

3. the damage threshold

For instance, a rule like : $\max H_{s}>5 m$ and $\max \eta>3 m$ over a time window uses the function $\left(\max \left(H_{S}\right), \max (\eta)\right)$, the time information : time window, and the damage thresholds $(5 ., 3$. $)$. In this case we would apply the function $\left(\max \left(H_{s}\right), \max (\eta)\right)$ over each cluster time window. Finally, the damages threshold (i.e., (5.,3.) in the example) is used to count the events and assign them to their respective categories.

\subsection{Return period}

The best rule functions will be used to compute the return period (RP) of the extreme events found in the historical investigations. The idea is to compute RP which values will be in some way representative of the associated damages. We 
Example of oceanic data, $H_{s}$ (blue) and $\eta$ (red) from a historical damaging event (delimited in time by the pink lines)

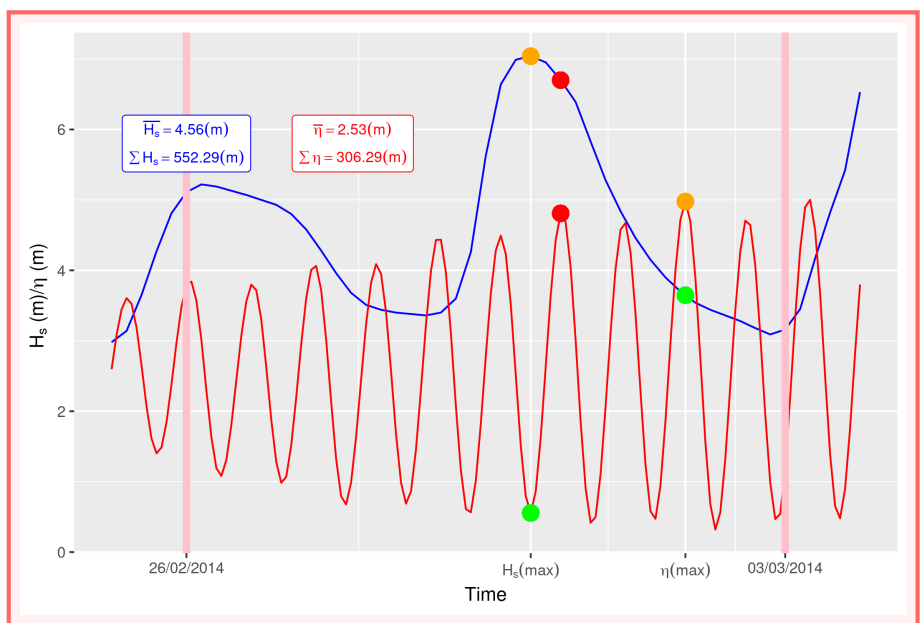

Hypothesis 1 : Peak values Hypothesis 2 : Cumulative values
Peak values explain damages. Three possibilities of event definition (with $H_{s}$ and $\eta$ in this example) :

1. Maxima along the whole duration (orange dots)

2. value of a variable when other is maximum (green dots)

3. value when probabilities is optimized (red dots - see equation 3)
Cumulative values explain damages. Two possibilities of event definition (with $H_{s}$ and $\eta$ in this example):

1. the means of each variable $\bar{y}_{i}$

2. the sums of each variable $\sum y_{i}$

Figure 3. Diagram summarizing the different possibilities of event definition based on data taken from the "Andrea" storm (between 26/02/2014 and 03/03/2014 as symbolized by pink lines). 


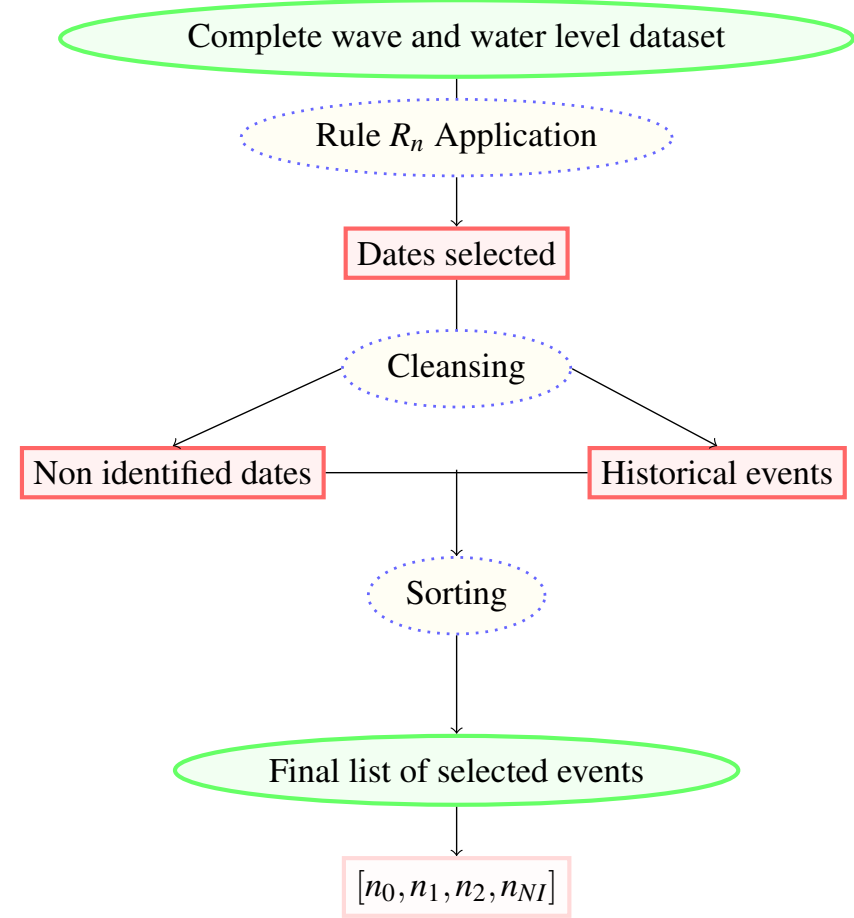

Figure 4. The three steps for validating damage rules with method $1: 1$ ) apply the rule to the entire dataset, 2) cleanse the dates identified in order to count only one per event, 3) sort the non identified dates between dates arguably attachable to events (close in time) and totally unknown ones. The result can take the form of a count of events based on the damages index $(0,1$ or 2) if the event is existing or NI for "Not identified".

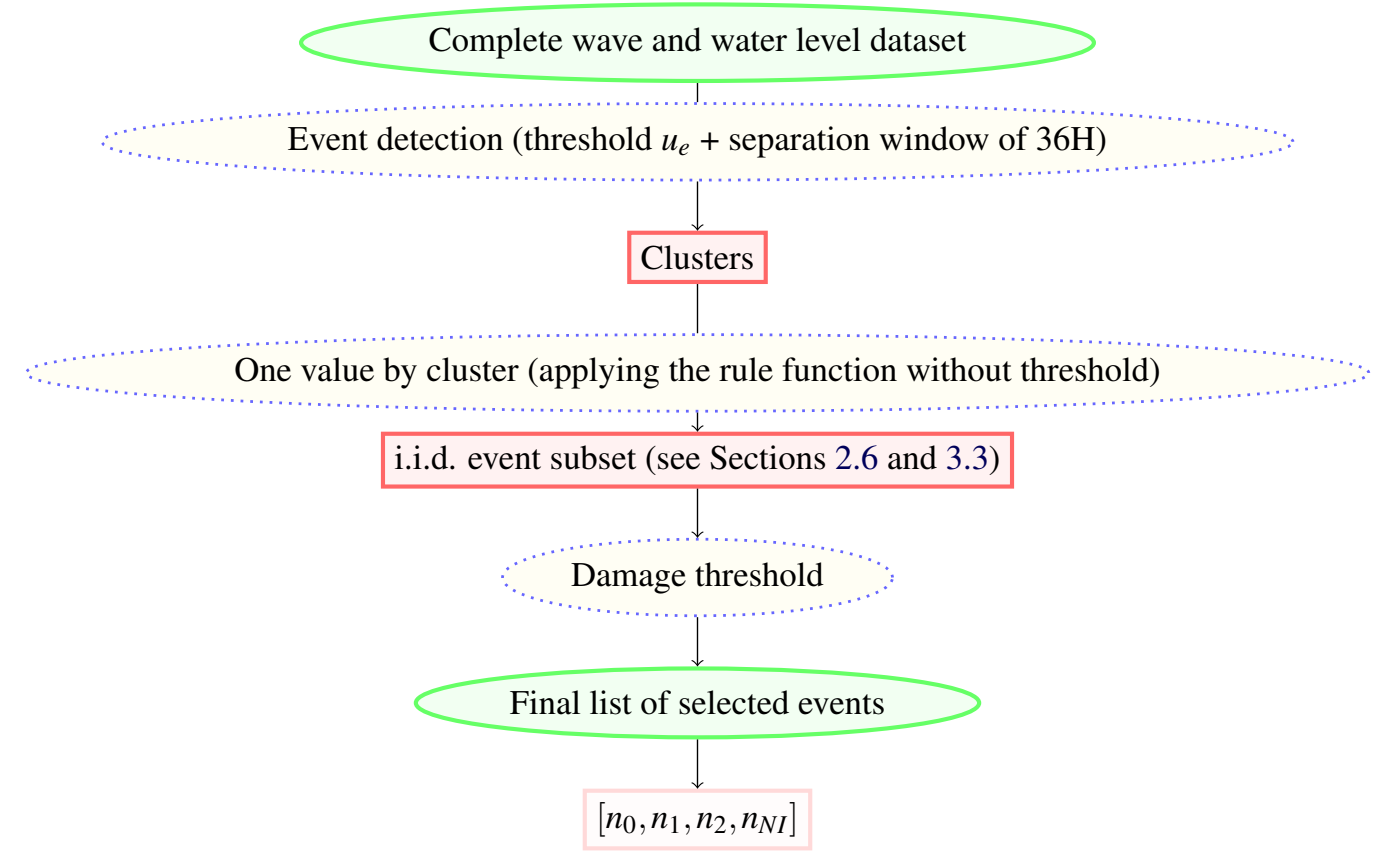

Figure 5. The two steps for validating damage rules with method $2: 1$ ) apply a threshold $u_{e}$ to the dataset to detect events at least separated by $36 \mathrm{H}$ (separation/merging procedure), 2) select one value by cluster by applying the rule function, 3 ) apply the rule damage threshold and count events. The result can take the form of a count of events based on the damages index $(0,1$ or 2) if the event is existing or NI for "Not identified". 
may for instance expect storm events showing the highest RP values to be associated to the most severe damages. This will be verified a posteriori in section 3.3.

Extreme value theory (EVT) provides statistical laws to describe extreme and rare events. To respect the EVT theoretical framework, these laws have to be applied to an i.i.d. subset of events obtained through a physical declustering procedure [4]. In the present study, the physical declustering is ensured by applying the method 2 described in the former section (see Figure 5). We will assume here that the oceanic random variables used in this study are homogeneously distributed. Regarding the independence hypothesis, we assume that the intermediate threshold procedure used in method 2 , the time lapse of $36 \mathrm{H}$ applied to separate clusters and the selection of an unique rule function value per cluster is sufficient to ensure the events independence.

The EVT distribution of the events subset is estimated using the Generalized Pareto Distribution (GPD) (see, e.g., [31]). The GPD can be used to represent the tail behavior of a random variable, when it exceeds a high threshold. For a random variable $\boldsymbol{x}$ and a fixed threshold $u$, the cdf of the GPD is given by

$$
G_{u, \sigma, \xi}(x)=1-\left[1+\xi \max \left(\frac{x-u}{\sigma}, 0\right)\right]^{-1 / \xi}, \quad x \geq u
$$

where $\sigma$ and $\xi$ are scale and shape parameters, respectively.

In this study, observations of the random variable $\boldsymbol{x}$ are denoted by $x(t)$, where $t \in \mathscr{T}$ is a date and $\mathscr{T}$ is a set of relevant dates within the $1949-2015$ period. Given a level $x$, the return period $R P(x)$ of the event $\{\boldsymbol{x}>x\}$ (see, e.g., [31]) can then be computed as

$$
R P(x)=\frac{\mu_{u}}{\widehat{\operatorname{Pr}}(\boldsymbol{x}>x)}=\frac{\mu_{u}}{1-G_{u, \hat{\sigma}, \hat{\xi}}(x)},
$$

where $\hat{\sigma}$ and $\hat{\xi}$ are the estimated scale and shape parameters, respectively,

$$
\mu_{u}=\frac{2015-1949+1}{\sum_{t \in \mathscr{T}} \mathbf{1}\{x(t)>u\}}
$$

and $\mathbf{1}\{x(t)>u\}$ is the indicator function which returns 1 when $x(t)>u$ and 0 otherwise.

As we shall see below, certain damage rules of interest involve two independent random variables $\boldsymbol{x}$ and $\boldsymbol{y}$. To model the joint distribution of $\boldsymbol{x}$ and $\boldsymbol{y}$, it thus suffices to model the distribution of $\boldsymbol{x}$ and $\boldsymbol{y}$ separately. As previously, we consider GPDs involving two thresholds $u_{\boldsymbol{x}}$ and $u_{\boldsymbol{y}}$ and estimate shape and scale parameters from the available time series $x(t)$ and $y(t)$. The return period of the event $\{\boldsymbol{x}>x, \boldsymbol{y}>y\}$ is then naturally computed as

$$
\begin{aligned}
R P(x, y) & =\frac{\mu}{\widehat{\operatorname{Pr}}(\boldsymbol{x}>x, \boldsymbol{y}>y)} \\
& =\frac{\mu}{\widehat{\operatorname{Pr}}(\boldsymbol{x}>x) \widehat{\operatorname{Pr}}(\boldsymbol{y}>y)} \\
& =\frac{\mu}{\left\{1-\hat{G}_{\boldsymbol{x}}(x)\right\}\left\{1-\hat{G}_{\boldsymbol{y}}(y)\right\}},
\end{aligned}
$$

where

$$
\mu=\frac{2015-1949+1}{\sum_{t \in \mathscr{T}} \mathbf{1}\left\{x(t)>u_{x}, y(t)>u_{y}\right\}} .
$$

A very important step, when using a GPD to modelize a phenomenon, is the choice of the threshold $u$. The literature provides several solutions to optimize the choice of $u$ based on either graphical, parametric or mixed methods. Usually a range of possible values is obtained. Here we needed preferably a single value for the reason explained hereafter.

The validation method 2 was actually developed in the perspective of the RP calculation with the following objectives

- use a validated rule function for the RP (to relate RP with damages),

- create a large i.i.d. events subset including the damaging events, hence the idea of an event detection procedure based on rule function with thresholds lower than the damage thresholds,

- compare threshold of the GPD with the rule damage threshold to verify that all the damaging events are properly modelized, hence the need for an unequivocal value.

To obtain the GPD threshold value, we relied on the method proposed by [32]. This method is based on a series of normality tests to find an appropriate threshold choice for a given data set.

\section{Results}

\subsection{Calibration of rules with the historical database}

In order to build rules consistent with damages observed during storm events, the first step is to investigate how the combinations of variables defined in Figure 3 are distributed when considering the 30 historical storms previously collected. Figure 6 presents the results obtained considering first source variables $\left(H_{s}, T_{p}, T_{m 10}, \eta\right)$. In each Figure, the maximum, mean and cumulative values are calculated over each storm duration. Note that the maximum value of separate variables (e.g., $H_{s}$ and $\eta$ ) can occur at different instants. We are seeking for combinations of variables for which storms of damage 0,1 and 2 are well discriminated. Clearly for source variables, the best indicator would be the maximum significant wave height 
combined with the maximum water level over the storm period. For instance a rule such as $H_{s_{\max }}>7 \mathrm{~m}$ and $\eta_{\max }>4.5 \mathrm{~m}$ correctly predicts most of the storms generating damages on the site ( 2 excepted, including the one with low confidence). It would be a little bit more delicate to discriminate level 2 damage storms from level 1. Considering mean wave height does not improve the discrimination, on the contrary, level 0 damage storms starts to be mixed with level 2 and 1 storms. The worst result is obtained with the cumulative significant wave height and water level for which there is no discrimination at all between damages. The maximum peak period along with maximum water level is also a possible alternative to rank storm damages. For instance $T_{p_{\max }}>16 \mathrm{~s}$ and $\eta_{\max }>4.4 m$ allows to gather all the storms which generated damages (excluding the one with low confidence), whereas the mean peak period is less discriminating and the cumulative peak period not relevant at all. The same results is obtained with the mean energetic period $T_{m 10}$, but the latter variable appears a little less discriminating than the peak period.

Figures 7 and 8 present results obtained with aggregated variables. A combination of the maximum wave energy flux and the maximum water level for an event shows a good performance at identifying damaging possibilities. With these variables, it is possible to clearly differentiate storms involving damages and storms with no damages $\left(P_{\max }>400 \mathrm{~J} . \mathrm{m}^{-1} . \mathrm{s}^{-1}\right.$ and $\eta_{\max }>4.42 \mathrm{~m}$ ), excluding the one with low confidence. It may also be possible to discriminate damage level from damage level 1 by increasing these two values. Considering mean wave energy flux and water level is not as accurate as considering the maximum values as storms of different damages starts to be mixed in the $2 \mathrm{D}$ plot while cumulative variables still appear inappropriate. Using maximum wave run-up and maximum water level is also a good combination to explain storm damages although slightly less discriminating than wave energy flux and water level with also always the same conclusions regarding the mean and cumulative variables.

We built the total water level (TWL) by adding the wave run-up to the water level (see Figure 8), which, we recall, included only tide and atmospheric surge signal. The total water level is commonly used as a predictor for storm flooding magnitude ([33], [34]). This time, a 1D plot is in theory sufficient to explore the relevance of this indicator. It is here plotted as a function of the mean wave direction to also have some insight on the role of this last variable. If we consider the maximum total water level, a simple rule such as $\eta_{\text {tot }_{\text {max }}}>$ $8.9 m$ allows to predict all the storms involving damages (but also including one with no damage). Again the mean variable is less accurate and the cumulative one not relevant. The mean wave peak direction during the storms appears very narrow with all the storms in a $15^{\circ}$ angle sector and with no preferential direction associated to a specific damage.

We also tested the simple response function $H_{s}+\eta$ defined in [5] in Figure 8 but the results appears less convincing than with the total water level based on [26].
Figure 9 shows results from simultaneous values for the energy flux $P$ and the water level $\eta$. The plots are built choosing the maximum of one variable during an event and then looking at the value of the other variable for the same sea state. The distinction between events seems to be better if the maximum of the energy flux is used to create the pair of value. Indeed, on the right panel of Figure 9 the separation between damaging and non damaging events is pretty obvious.

Figure 10 represents the plots obtained with the variable $I$ from the formula (3) using the energy flux $P$ and the water level $\eta$. Using $I$ as a rule to identify damaging storms from the others may be difficult as shown by the cluster mixing minor and major storms for $I>0.96$ in Figure 10 (a). A rule based on the simultaneous values of $P$ and $\eta$ could be used even though few important storms are left aside by this rule.

Among all of these results we decided to keep 8 damage rules which if they are encountered potentially lead to an event responsible of damages. These rules are listed below as rules :

R1 : $\max H_{s}>7 m$ and $\max \eta>4.5 m$ (Figure 6 (a)) ;

R2 : $\max T_{p}>16 s$ and $\max \eta>4.4 m$ (Figure $\left.6(\mathrm{~b})\right)$;

R3 : $\max P>400 \mathrm{~J} . \mathrm{m}^{-1} \cdot s^{-1}$ and $\max \eta>4.42 m$ (Figure 7 (a)) ;

R4 : $\max R_{2 \%}>4.4 m$ and $\max \eta>4.4 m$ (Figure 7) (b) ;

R5 : $\max \left(\eta+R_{2 \%}\right)>8.9 m$ (Figure 8$)(\mathrm{a})$;

R6 : $P>400 J . m^{-1} . s^{-1}$ and $\eta>4 m$ at the same date (Figure 9 (b)) ;

R7 : $H_{s}+\eta>11.5 m($ Figure 8$)(\mathrm{b})$;

R8 : $I>0.96$ (Equation (3) and Figure 10).

\subsection{Validation of the rules}

To estimate the efficiency of each rule, we test them to the entire dataset.

\subsubsection{Method 1 : direct rule application}

Since, the rules $\mathbf{R 5}, \mathbf{R 6}, \mathbf{R 7}$ and $\mathbf{R 8}$ do not use two non simultaneous maxima they can be written :

$\mathbf{R 5}(t): \eta(t)+R_{2 \%}(t)>8.9 m ;$

R6(t) : $P(t)>400 J . m^{-1} . s^{-1}$ and $\eta(t)>4 m$;

$\mathbf{R 7}(t): H_{s}(t)+\eta(t)>11.5 m$

$\mathbf{R 8}(t): I(t)>0.96$.

The other rules need a time window $\tau$ to be specified, which represents the number of tidal cycles taken before each tested date. We tested two different values for $\tau$ to show the result dependency on this parameter : $\tau=6$ (i.e., 3 days) and a little shorter window of 4 tidal cycles (i.e.,2 days). Note that the average of the storms duration in Table 1 is 3 days. These rules can be written as : 


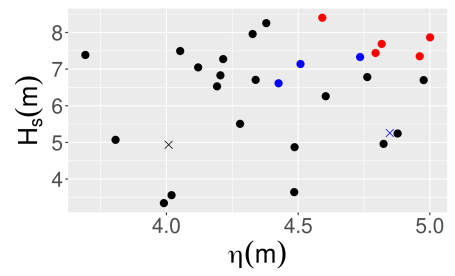

(a1)

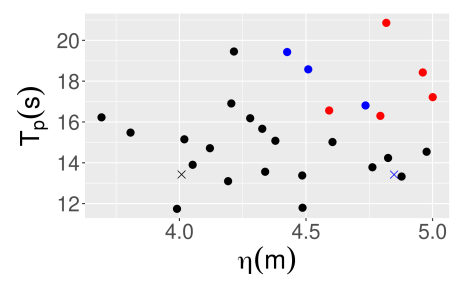

(b1)

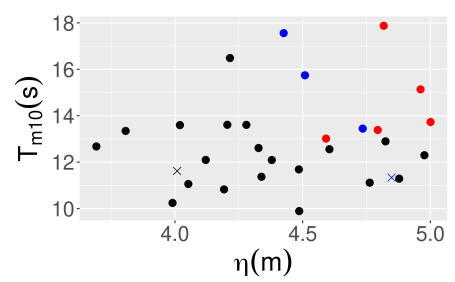

(c1)

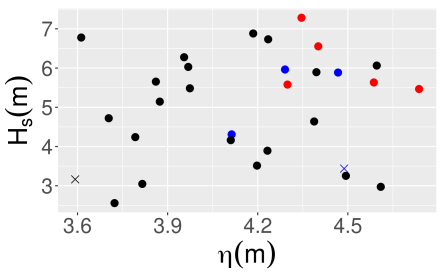

(a2)

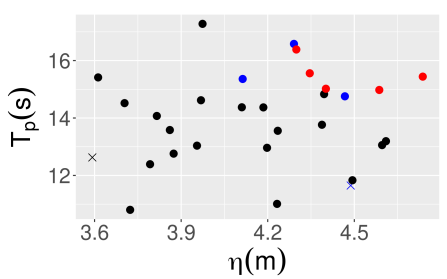

(b2)

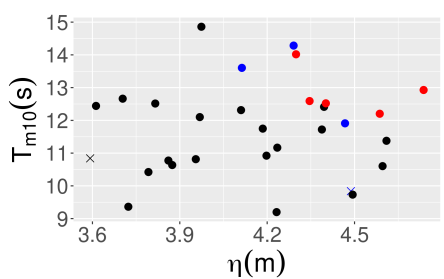

(c2)

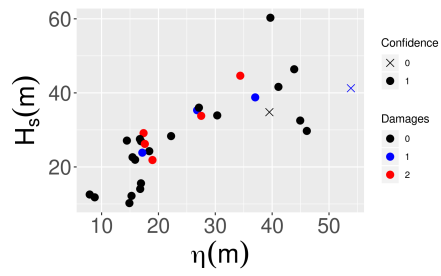

(a3)

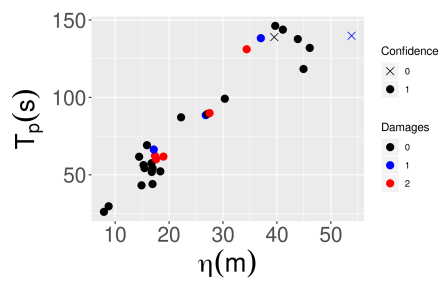

(b3)

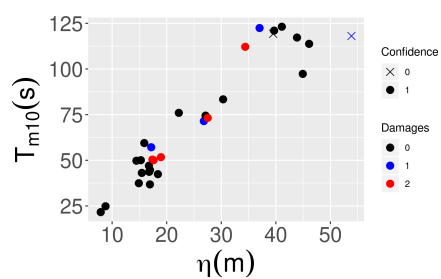

(c3)

Figure 6. Significant wave height $H_{s}$ (a)/ peak period $T_{p}$ (b) / energetic period $T_{m 10}$ (c) versus water level, (1) maximum values calculated for both variables over storm duration, (2) mean values for both variables over storm duration, (3) cumulative values for both variables over storm duration. Damage level : 0 (black), 1 (blue), 2 (red) (points represented by a cross "+" are data of low confidence see Table 1).

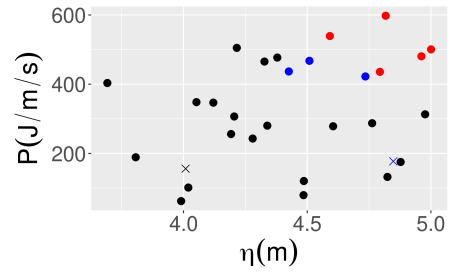

(a1)

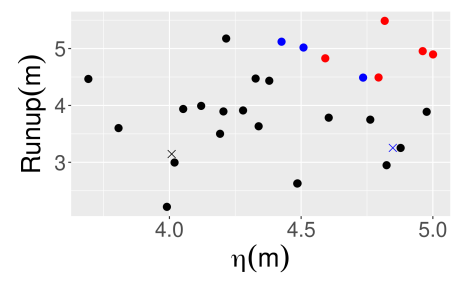

(b1)

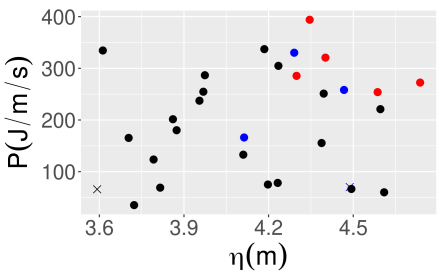

(a2)

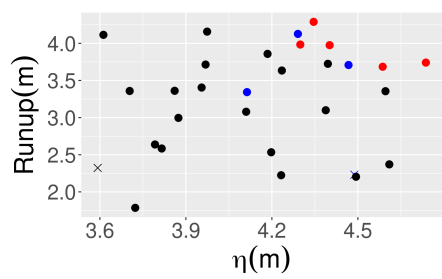

(b2)

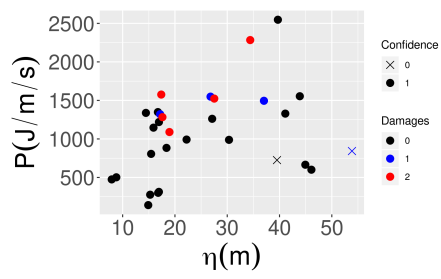

(a3)

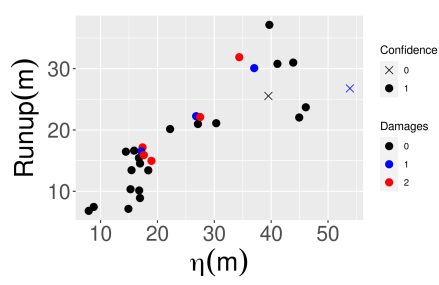

(b3)

Figure 7. Energy flux $P$ (a) / wave run-up $R_{2} \%$ as calculated by Stockdon's formula (b) versus water level, (1) maximum values calculated for both variables over storm duration, (2) mean values for both variables over storm duration, (3) cumulative values for both variables over storm duration. Damage level : 0 (black), 1 (blue), 2 (red) (points represented by a cross " +" are data of low confidence see Table 1). 


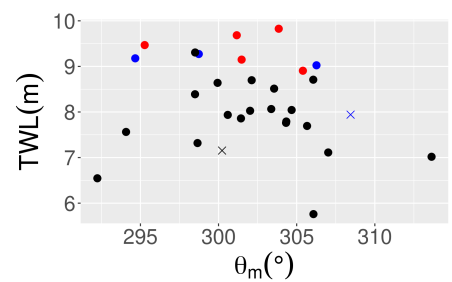

(a1)

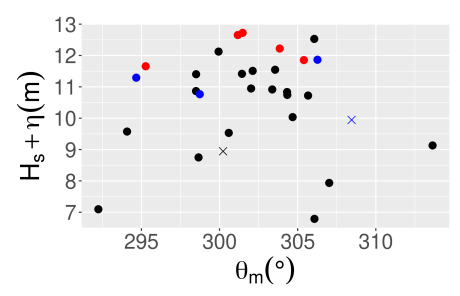

(b1)

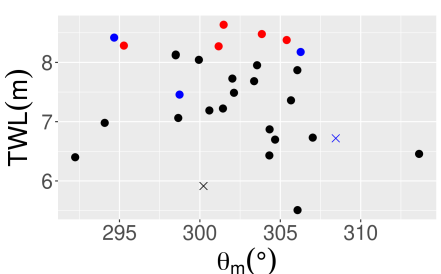

(a2)

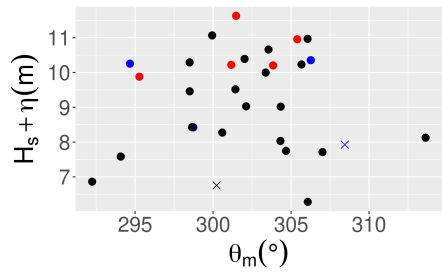

(b2)

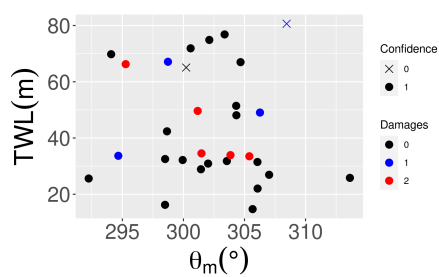

(a3)

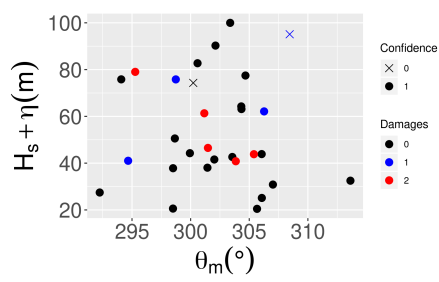

(b3)

Figure 8. Total water level (a) / $H_{s}+\eta$ (b) versus mean wave direction over storm duration. (1) maximum value of total water level $/ H_{s}+\eta$ over storm duration, (2) mean value of total water level / $H_{s}+\eta$, (3) cumulative value of total water level / $H_{s}+\eta$.

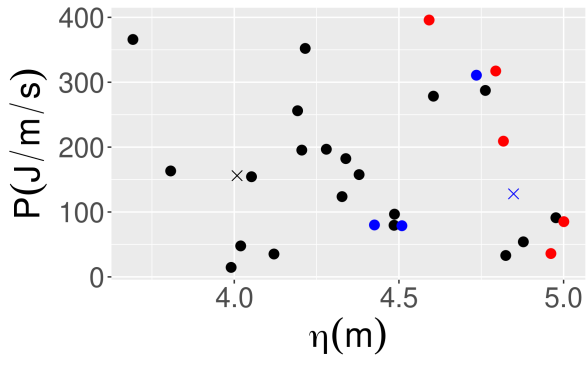

(a)

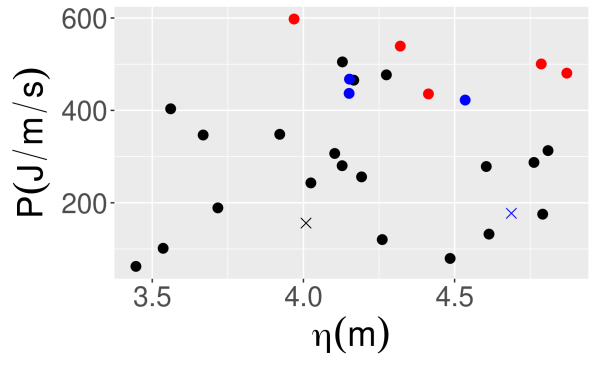

(b)

Figure 9. Wave energy flux versus water level (a) values of $P$ taken when $\eta$ is maximum (b) values $\eta$ taken when $P$ is maximum

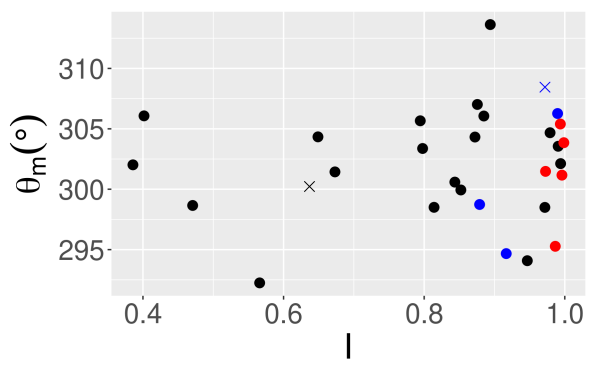

(a)

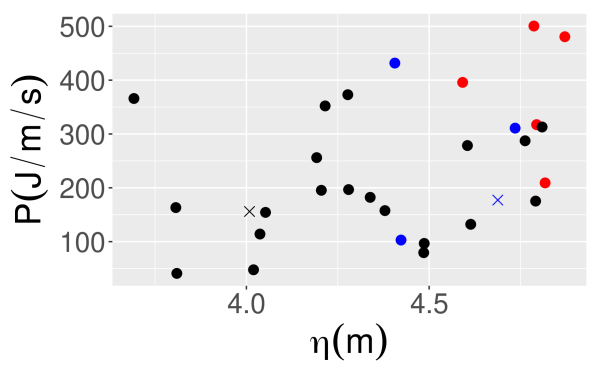

(b)

Figure 10. (a) storms as a function of the maximum $I$ (in x-axis) and the average of $\theta_{m}$ (y-axis). (b) storms as a function of water level $\eta$ at maximum of I (x-axis) and wave power $P$ at maximum of I (y-axis) 


$$
\begin{aligned}
& \mathbf{R} 1(t, \tau): \max \left\{H_{s}(t), H_{s}\left(t_{-1}\right), \ldots, H_{s}\left(t_{-\tau}\right)\right\}>7 \mathrm{~m} \\
& \text { and } \max \left\{\eta(t), \eta\left(t_{-1}\right), \ldots, \eta\left(t_{-\tau}\right)\right\}>4.5 \mathrm{~m} ; \\
& \mathbf{R 2}(t, \tau): \max \left\{T_{p}(t), T_{p}\left(t_{-1}\right), \ldots, T_{p}\left(t_{-\tau}\right)\right\}>16 \mathrm{~s} \\
& \quad \text { and } \max \left\{\eta(t), \eta\left(t_{-1}\right), \ldots, \eta\left(t_{-\tau}\right)\right\}>4.4 \mathrm{~m} ; \\
& \mathbf{R 3}(t, \tau): \max \left\{P(t), P\left(t_{-1}\right), \ldots, P\left(t_{-\tau}\right)\right\}>400 \mathrm{~J} . \mathrm{m}^{-1} . \mathrm{s}^{-1} \\
& \quad \text { and } \max \left\{\eta(t), \eta\left(t_{-1}\right), \ldots, \eta\left(t_{-\tau}\right)\right\}>4.42 \mathrm{~m} ; \\
& \mathbf{R} 4(t, \tau): \max \left\{R_{2 \%}(t), R_{2 \%}\left(t_{-1}\right), \ldots, R_{2} \%\left(t_{-\tau}\right)\right\}>4.4 \mathrm{~m} \\
& \quad \text { and } \max \left\{\eta(t), \eta\left(t_{-1}\right), \ldots, \eta\left(t_{-\tau}\right)\right\}>4.4 \mathrm{~m} .
\end{aligned}
$$

The 8 rules are tested against the whole dataset $(48000$ dates) to count how many events are detected. The results are summarized in the Table 2.

To properly understand the numbers presented in columns "events", further explanations are required. The rules are binary. Indeed, due to the limit of the damage data used, it was not possible to discriminate level 1 and level 2 damage events with any of the rules. Consequently, a rule returns 1 , when it is fulfilled and 0 when it is not and only determine if damages can be expected without specifying the damage level. To fill columns "0", "1", "2" and "Non identified dates", we compare these binary values with the events presented in Table 1. If a rule returns 1 when the date corresponds to an identified damage event, the corresponding column, either "1" or " 2 ", is incremented. If the rule returns 1 for a date identified in Table 1 with 0 damage, column " 0 " is incremented. Finally, if the rule returns 1 for a non identified date (i.e. in Table 1), column "Non identified dates" is incremented. Hence a perfect rule will give $0,4,5$ (i.e., the respective numbers of level 1 and 2 events), 0 , respectively for columns " 0 ", " 1 ", "2", "Non identified dates".

This optimum result is not obtained with any rule. Nevertheless, except for rules $\mathbf{R 2}$ and $\mathbf{R 8}$ which lead to a lot of false positives, every rule shows relatively good performance in detecting events, the best ones being $\mathbf{R 1}, \mathbf{R 3}$ (the best rule) and $\mathbf{R 4}$, therefore the rules using a time window but not only wave period as wave parameter. We also note that the results depends moderately on the time window value.

\subsubsection{Method 2 : preliminary event detection}

In this section, we tested the most efficient rules (i.e. rules R1, $\mathbf{R 3}$ and R4) of the previous section along with rules $\mathbf{R 5}$ and R6, which will be used in the return period computation. We recall that method 2 uses an intermediate threshold procedure to detect the events (Figure 5).

The following event thresholds have been found to give satisfactory results in the rules validation :

$$
\begin{aligned}
& \text { R1 }: \eta>4.0 m \text { and } H_{s}>3.0 m \\
& \text { R3 }: \eta>3.0 m \text { and } P>90.0 J . m^{-1} . s^{-1} \\
& \text { R4 : } \eta>2.0 m \text { and } R_{2} \%>3.0 m \\
& \text { R5 : } \eta+R_{2} \%>6.5 m \\
& \text { R6 : } \eta>4.0 m \text { and } P>100.0 J . m^{-1} . s^{-1}
\end{aligned}
$$

Next the rest of the procedure described in Figure 5 is applied. The results are presented in Table 3. They are consistent with the results of the previous method, the rule $\mathbf{R} 3$ still being the most efficient rule. We note that the choice of the first threshold(s) used to create the clusters depends on the rule function considered and possibly on the site studied. Therefore, it is better to be guided by historical data to perform this operation as in the present study. As an example, considering the simplest rule, $\mathbf{R 5}$, a too low event threshold $\left(u_{e}=5.0 \mathrm{~m}\right.$ for instance) leads to missing a few important historical events because of their temporal proximity. Conversely, a too high threshold ( $8.5 \mathrm{~m}$ here) will reduce the average size of clusters and finally lead to more false positives.

\subsection{Estimation of storm return periods}

We selected rules R3, R5 and R6 to illustrate flood return period calculations. $\mathbf{R 3}$ is one of the two best rules, based on the same variables as R6, but authorizing based on non simultaneous maxima. RP were also calculated with rule R1, which is equivalent to $\mathbf{R 3}$ in terms of damages representativity, but results are not showed here to lighten the manuscript. Nevertheless comments are provided at the end of this section regarding this rule. $\mathbf{R 5}$ is an easy rule using only one variable : the total water level (TWL). TWL is a common variable used to characterize the flooding hazard at large scale (e.g.,[7], [? ]). R6 uses the same variables as $\mathbf{R 3}$ but considering simultaneity. This last rule is also retained to illustrate the importance of this calculation choice in the RP final result.

For R5, the total water level $\boldsymbol{\eta}+R_{2} \%$ was computed for every date in the dataset. The i.i.d. subset is obtained with a first arbitrary threshold $u_{e}=6.5 \mathrm{~m}$ (corresponding to the quantile $91.4 \%$ of the original time series). This operation reduced the time series to 924 clusters. Since $\mathbf{R 5}$ relies on the maximum of $\eta+R_{2} \%$ during an event, each cluster is then defined by its maximum value of $\eta+R_{2} \%$. The threshold calculated following [32] is $u=7.26 \mathrm{~m}$. This threshold is then used to estimate the parameters of the GPD. The following values are obtained for the GPD parameters : $\hat{\sigma}=0.67$ and $\hat{\xi}=-0.16$. The mathematical threshold is in this case significantly lower than the damage threshold (i.e. $8.9 \mathrm{~m}$ ), which ensures to take into account properly all the events with damages.

The rule R6 is based on simultaneous values of $\eta$ and $P$. The damage thresholds of R6 were obtained in Figure 9 b) which means that the water level $\eta$ is taken when the wave energy flux $P$ is maximum. The clusters are created with a single threshold $u_{e_{\eta}}=4 \mathrm{~m}$ (quantile $64.4 \%$ ) to avoid situations combining a low water level with a high wave energy flux. Then, the value of the maximum of $P$ in each cluster is selected to represent the event, the first thresholding on $\eta$ ensuring a high water levels. The algorithm of [32] gives for the flux $P$ a threshold of $406.63 \mathrm{~J} . \mathrm{m}^{-1} . \mathrm{s}^{-1}$ and for $\eta 4.20 \mathrm{~m}$. In this case, the mathematical thresholds are slightly higher than the damage thresholds (i.e., respectively $400 \mathrm{~J} . \mathrm{m}^{-1} . \mathrm{s}^{-1}$ and $4.00 \mathrm{~m}$ ) illustrating a situation where a few damaging events RP may not be properly modeled. With these thresholds, 


\begin{tabular}{|c|c||c|c|c|c|}
\hline \multicolumn{2}{|c||}{ Rules } & \multicolumn{4}{|c|}{ Events } \\
\hline Rule & Variables & $\mathbf{0}$ & $\mathbf{1}$ & $\mathbf{2}$ & Non identified dates \\
\hline $\mathbf{R} 1(t, \mathbf{4})$ & $\max H_{s}, \max \eta$ & 0 & 2 & 5 & 3 \\
$\mathbf{R 1}(t, \mathbf{6})$ & $\max H_{s}, \max \eta$ & 1 & 2 & 5 & 3 \\
$\mathbf{R 2}(t, \mathbf{4})$ & $\max T_{p}, \max \eta$ & 1 & 3 & 5 & 41 \\
$\mathbf{R 2}(t, \mathbf{6})$ & $\max T_{p}, \max \eta$ & 1 & 3 & 5 & 58 \\
$\mathbf{R 3}(t, \mathbf{4})$ & $\max P, \max \eta$ & 0 & 3 & 5 & 4 \\
$\mathbf{R 3}(t, \mathbf{6})$ & $\max P, \max \eta$ & 2 & 3 & 5 & 4 \\
$\mathbf{R 4}(t, \mathbf{4})$ & $\max R_{2 \%}, \max \eta$ & 1 & 3 & 5 & 3 \\
$\mathbf{R} 4(t, \mathbf{6})$ & $\max R_{2 \%}, \max \eta$ & 2 & 3 & 5 & 6 \\
$\mathbf{R 5}(t)$ & $R_{2 \%}+\eta$ & 1 & 3 & 5 & 12 \\
$\mathbf{R 6}(t)$ & $P, \eta$ & 3 & 3 & 5 & 10 \\
$\mathbf{R 7}(t)$ & $H_{s}+\eta$ & 4 & 1 & 5 & 12 \\
$\mathbf{R 8}(t)$ & $I$ & 4 & 2 & 5 & 29 \\
\hline Historical listed events & $\mathbf{2 1}$ & $\mathbf{4}$ & $\mathbf{5}$ & \\
\hline
\end{tabular}

Table 2. Method 1 rules validation results for $\tau=4$ and $\tau=6$. For each rule, the number of identified category 0,1 or 2 events is given along with the number of unrecorded events in the historical dataset. It should be remembered that, during the latter, of the 30 events listed, 21 (respectively 4,5$)$ were Category $0(1,2$, respectively). The number of false positives is obtained by adding up the numbers in column "0" and the column "Non identified dates".

\begin{tabular}{|c|c||c|c|c|c|}
\hline \multicolumn{2}{|c||}{ Rules } & \multicolumn{4}{|c|}{ Events } \\
\hline Rule & Variables & $\mathbf{0}$ & $\mathbf{1}$ & $\mathbf{2}$ & Non identified dates \\
\hline R1 & $\max H_{s}, \max \eta$ & 1 & 1 & 5 & 4 \\
R3 & $\max P, \max \eta$ & 1 & 2 & 5 & 5 \\
R4 & $\max R_{2 \%}, \max \eta$ & 1 & 1 & 5 & 6 \\
R5 & $R_{2 \%}+\eta$ & 1 & 3 & 5 & 12 \\
R6 & $P, \eta$ & 3 & 2 & 5 & 11 \\
\hline \multicolumn{2}{|l|}{ Historical listed events } & $\mathbf{2 1}$ & $\mathbf{4}$ & $\mathbf{5}$ & \\
\hline
\end{tabular}

Table 3. Method 2 rules validation results. For each rule, the number of identified category 0,1 or 2 events is given along with the number of unrecorded events in the historical dataset. It should be remembered that, during the latter, of the 30 events listed, 21 (respectively 4,5$)$ were Category $0(1,2$, respectively). The number of false positives is obtained by adding up the numbers in column " 0 " and the column "Non identified dates". 
the associated GPD parameters are respectively : $\hat{\sigma}_{P}=0.28$, $\hat{\xi}_{P}=-0.29$, and $\sigma_{P}=118.28, \hat{\xi}_{P}=-0.63$. Since, the independence is suggested by the Kendall's $\tau$, equation 8 can be employed to estimate the joint probability.

The rule $\mathbf{R 3}$ is based on not necessarily simultaneous maxima of two variables : $P$ and $\eta$. To create the subset of events, the following event thresholds were used : $u_{e_{\eta}}=3 \mathrm{~m}$ and $u_{e_{P}}=90 \mathrm{~J} . \mathrm{m}^{-1} \cdot \mathrm{s}^{-1}$. These values correspond respectively to the minimum of the time series of $\eta$ and to the quantile $95.1 \%$ of the wave energy flux $P$ time series. The resulting dataset contains 711 clusters. For each cluster, the maxima of each variable is selected. The algorithm of [32] gives the values $u_{P}=331.24 \mathrm{~J} . \mathrm{m}^{-1} . \mathrm{s}^{-1}$ and $u_{\eta}=4.039 \mathrm{~m}$ respectively for the flux and water level. Those values are lower than the damage thresholds (i.e., $400 \mathrm{~J} . \mathrm{m}^{-1} . \mathrm{s}^{-1}$ and $4.42 \mathrm{~m}$ ) ensuring all the damaging event to be properly modeled. With these thresholds, the respective GPD parameters are $\hat{\sigma}_{\eta}=0.46$, $\hat{\xi}_{\eta}=-0.44$ and $\hat{\sigma}_{P}=127.83, \hat{\xi}_{P}=-0.37$. The test based on Kendall's $\tau$ coefficient does not reject independence between the two variables composing the event dataset, allowing the use of equation (8) to estimate the joint probability.

The RP obtained with the three rules are presented in Tables 4, 5 and 6. In these tables, we added the events name or index, and the damage level if it exists.

Ideally, level 2 damage events should appear first in these tables followed by level 1 events and then the rest of the identified or non identified events. As expected, rule $\mathbf{R 3}$ give the best results to this respect gathering the five category 2 events in the seven first positions. Rule $\mathbf{R 5}$ ranks the last level 2 event at the 18 th position and rule $\mathbf{R 6}$ at the 9 th position. In table 6, the date 1965-01-21 seems very close to the end of the event 4 of Table 1, which was qualified as a damage level 1 storm. It is therefore very plausible that the two events may actually be the same one. This raises the question of precision in the historical data, especially regarding the dates of the events. In the fifth position, the date 2008-03-11, which did not appear first in the archives and press research, is actually storm "Johanna", well known for its impact in the northern part of the french Atlantic coast [35]. A quick check in the press documents reveals that this event also had a significant impact with severe damages at locations surrounding Biarritz Grande Plage such as Saint Jean de Luz, Guetary or Capbreton. Nevertheless, it was not possible to find evidences of damage at La Grande Plage by investigating retrospectively the town hall archives and the press. As a consequence, this storm may be recategorized as level 1 damage storm with 0 confidence but not more.

When comparing the three tables, it is obvious that the RP of a particular event strongly depends on the rule applied to define the event subset. For instance, the RP of Hercules appears very different depending on the rule (i.e., 21 years for R5, 101 year for $\mathbf{R 3}$ and 1.78 year for R6). This discrepancy stresses the importance of the event subset creation in the RP calculation. But the discrepancy is also caused by the relative short duration of the dataset and the occurrence of a very energetic winter (i.e., 2013-2014) involving 3 huge storms appearing in the 4 first positions in the three tables. The limit of the dataset compared to the event intensity measured is illustrated in Figure 11 showing the extrapolation plot with the associated uncertainty for rule R5. It appears clearly from this plot that large RP values can not be totally trusted.

Finally, note that RP calculated with $\mathbf{R} 1$ are also ranked consistently with damages, the five level 2 events being included in the seven highest RP (results not presented here). Nevertheless, the order is different compared to $\mathbf{R} 3$ and the individual value of the event RP also significantly differs.

\section{Discussion}

In this paper, impact is included at the initial stage of coastal flooding events definition by intercomparing rules based on waves and water level parameters to a damage dataset obtained from recent historical records in the Biarritz Grande Plage, French Basque coast. A relatively comparable approach is developed in [15]. In this study, a continuous hydrometeorological and damage event database was build with the same type of event categorization (i.e. 2 levels with a confidence index) as presented in the present study and earlier in [20]. Then, a numerical model is used to retrospectively analyze damage events and, when needed, correct the damage data. Finally, the return period is computed for historical flood events. Hence, [15] proposes an original composite approach based on historical data and numerical simulation to better understand past flood events. In the present paper, elaborated rules based on maximal, mean, integral values of source and aggregated variables over storm duration, combining waves and water level, were used and confronted to the damage database. This allowed to identify the rules able to explain damages with their associated threshold. Then, the rules skill was retrospectively tested over the total time span, showing the existence of efficient rules, which could be potentially used for damage prediction for future events. Finally, the best skilled rules were used to estimate RP, allowing to relate this key parameter to the damage level.

This work allows first to refine our understanding on the respective role of wave parameters and water level in flood induced damages. As evidenced for instance by Figure 6, the knowledge of the wave height alone (even taken at high tide) is obviously not sufficient to characterize damaging floods. The same conclusion holds for the water level $\eta$ if considered alone. The two parameters have to be combined to explain damages. Moreover, the wave period has to be accounted for in the rule, for instance through the wave energy flux or the run-up as in this study. A good illustration of these two statements is the Hercules storm, which occurred in January 2014 and caused significant damages to the basque coast. The latter was first not recognized as Natural Catastrophe (i.e., the CATNAT statement) by the french Ministry of Interior, which characterizes storm strength through their RP in wave height and water level. Wave height and water level were indeed not extreme (i.e., about 1 year RP for the wave height, 


\begin{tabular}{|ccccc|}
\hline Date & Name & Damages & $\eta+R_{2 \%}$ & Return Period \\
\hline $02 / 02 / 2014$ & Nadja & 2 & 9.83 & 73.79 \\
$04 / 03 / 2014$ & Christine & 2 & 9.68 & 43.53 \\
$21 / 01 / 1965$ & & & 9.64 & 37.46 \\
$07 / 01 / 2014$ & Hercules & 2 & 9.47 & 21.13 \\
$11 / 03 / 2008$ & & & 9.41 & 17.82 \\
$16 / 02 / 2011$ & Quirin & 0 & 9.31 & 12.89 \\
$30 / 12 / 1998$ & 14 & 1 & 9.27 & 11.69 \\
$13 / 02 / 1979$ & & & 9.21 & 9.91 \\
$31 / 01 / 1990$ & 12 & 1 & 9.18 & 8.95 \\
$29 / 12 / 1951$ & 1 & 2 & 9.15 & 8.28 \\
$03 / 02 / 1961$ & & & 9.15 & 8.23 \\
$13 / 12 / 1978$ & & & 9.11 & 7.49 \\
$06 / 03 / 1959$ & & & 9.10 & 7.18 \\
$13 / 12 / 1982$ & & & 9.06 & 6.52 \\
$25 / 12 / 1965$ & & & 9.00 & 5.55 \\
$13 / 01 / 1951$ & & & 8.94 & 4.78 \\
$10 / 12 / 2007$ & & & 8.91 & 4.46 \\
$09 / 11 / 2010$ & 20 & 2 & 8.90 & 4.40 \\
$12 / 12 / 1957$ & & & 8.90 & 4.30 \\
$26 / 02 / 1978$ & & & 8.86 & 3.96 \\
$01 / 03 / 1972$ & & & 8.80 & 3.45 \\
\hline
\end{tabular}

Table 4. List of storms ranked by decreasing RP based on rule R5. In pink, events not reported in the damage database (Table 1).

and a little less than 2 for the water level) when considered separately. Nevertheless, as Hercules is also characterized by an abnormally high wave period, it appears as the most extreme event (Table 6) in our RP calculation based on the rule using the wave energy flux (hence, including the wave period) and the water level. Thanks to this result, this particular event was finally upgraded to the CATNAT level.

With two variables, there is a wide range of combinations to define an event and its probability. The usual probabilities considered are [36]: $P_{A N D}=\mathbb{P}[U>u \cap V>v], P_{O R}=\mathbb{P}[U>$ $u \cup V>v], P_{C O N D 1}=\mathbb{P}[V>v \mid U>u], P_{C O N D 2}=\mathbb{P}[V>$ $v \mid U \leq u$. [6] highlights the link between the probability, the event definition, the sampling, the return period and its meaning. In the present paper, the rules defining events are related to the damage occurrence. Rules based on a response variable excepted (i.e., R5, R7 and R8), all the rules defined in this work, involving two variables and explaining damages, are based on a relationship such as $U>u \cap V>v$. This tends to show that $P_{A N D}$ may be the relevant probability to characterize the risk for environments similar to the study site.

Second, the different Figures (6 to 10) presented in this paper give some indications about the relationship between input parameters (i.e., waves and water level) and impact (i.e.,damages). Indeed, good results for the explanation of damages are consistently obtained when combining the maximal values of a wave related variable with the maximal value of a water level related one (e.g., $\max \left(H_{s}\right)$ and $\max (\eta)$, $\max (P)$ and $\max (\eta)$, etc.) compared to the mean parameters and the integral or accumulated parameters. This result tends to show that, in our case, damages are related to a combination of extreme waves and water levels of short duration rather than the repetition of lower meteorological conditions. One explanation of this result may be the configuration of the study site and the presence of the seawall in front of the buildings (Figure 2) which protection effect may quickly drop to zero when the total water level exceeds the freeboard. The best results are obtained with rules based on non simultaneous maxima. This is an interesting information, showing that a proper automatic event definition may require more than one date to be accurate and account for the complexity and variability of the events. Mean values of source parameters on storm duration could also be used as damage rule as evidenced for instance in Figures 7 (b) and 8 (b) but they are a little less efficient than the maximum values. On the contrary, accumulated values are not at all representative of damages for the studied site. Obviously, this conclusion is only valid for the site considered in this study and accumulated or mean values may be very relevant to describe beach erosion or damages to a breakwater block armor unit for instance.

As evidenced by Table 2, most of the rules tested in this paper are actually correct predictor of damages (exception made of the ones involving the wave period or $I$ which found too many false positives). Therefore, they are consistent to define events for sampling and calculate a return period. Moreover, those rules are logical rules already used in the literature. Nevertheless, one striking conclusion of the paper is that, if the rules are good to predict damages, their application to calculate RP leads to very different results. The difference 


\begin{tabular}{|cccccc|}
\hline Date & Name & Damages & Flux & Level & RP \\
\hline $21 / 01 / 1965$ & & & 584.99 & 4.70 & 243.90 \\
$02 / 02 / 2014$ & Nadja & 2 & 480.64 & 4.87 & 22.63 \\
$04 / 03 / 2014$ & Christine & 2 & 500.52 & 4.79 & 13.05 \\
$11 / 03 / 2008$ & & & 494.20 & 4.57 & 2.57 \\
$29 / 12 / 1951$ & 1 & 2 & 539.15 & 4.32 & 1.99 \\
$07 / 01 / 2014$ & Hercules & 2 & 550.12 & 4.11 & 1.78 \\
$10 / 12 / 2007$ & & & 539.49 & 4.10 & 1.27 \\
$16 / 02 / 2011$ & Quirin & 0 & 504.96 & 4.13 & 0.59 \\
$09 / 11 / 2010$ & 20 & 2 & 435.66 & 4.41 & 0.55 \\
$08 / 02 / 1996$ & 13 & 0 & 476.93 & 4.27 & 0.50 \\
$25 / 12 / 1965$ & & & 479.66 & 4.25 & 0.47 \\
$13 / 12 / 1982$ & & & 481.06 & 4.07 & 0.40 \\
$13 / 12 / 1978$ & & & 467.78 & 4.20 & 0.34 \\
$30 / 01 / 1990$ & 12 & 1 & 467.62 & 4.15 & 0.34 \\
$26 / 02 / 1989$ & 11 & 0 & 465.42 & 4.17 & 0.33 \\
$30 / 12 / 1998$ & 14 & 1 & 436.81 & 4.15 & 0.24 \\
$13 / 01 / 1951$ & & & 434.37 & 4.07 & 0.23 \\
$13 / 02 / 1979$ & & & 403.58 & 4.25 & 0.22 \\
$06 / 02 / 1950$ & & & 416.72 & 4.18 & 0.20 \\
$13 / 03 / 1976$ & & & 412.96 & 4.02 & 0.19 \\
$03 / 02 / 1961$ & & & 411.48 & 4.17 & 0.19 \\
\hline
\end{tabular}

Table 5. List of storms ranked by decreasing RP based on rule R6. In pink, events not reported in the damage database (Table 1)

observed is still not acceptable from the point of view of the stakeholder who has to make decision based on these RP. With the rules $\mathbf{R 3}$ (and $\mathbf{R 1}$ ), at least we reached a classification in terms of RP, consistent with the damages found in the archives or in the press. This was not really the case with the other rules. A clear relationship between damage and RP is important to ensure a simple appropriation of the RP concept by stakeholders. Nevertheless, from the results of the paper, it seems that there is still significant work to be done to ensure that each individual storm potential impact is assessed accurately on an appropriate metric respecting the point of view defended in this paper.

There are several limitations in our study which have to be pointed out. First, the conclusions of the paper are very site-specific. It has to be stressed because different conclusions may be obtained in other places for instance dominated by atmospheric storm surges. Biarritz is a place where waves and tide level drive the risk level. More over the study is also very local as being restricted to a specific beach which behavior may be very much influenced by its configuration and especially the presence of a seawall. The paper is also based on a limited database. Even though building such a database appeared to be extremely time consuming, it implies some limitations mainly due to the heterogeneity and incompleteness of the data sources. The wave hindcast is also flawed by several inherent inaccuracies. Nevertheless, the somehow good correspondence obtained in the paper when building the rules is for this aspect encouraging.

Finally, another limitation of this study is the unknown beach profile variability over time during the studied period and its effect on the damages induced by coastal flooding. Here the beach slope only appears explicitly in the rules involving run-up. To provide an insight of the role played by this parameter in the rule efficiency, we have plotted, in Figure 12 the maxima of run-up during historical events for two cases :

1. A constant beach slope with $\beta=0.09$ (similar to Figure 7 but without applying the quantile distribution correction)

2. For each event, one random beach slope is sampled from a uniform distribution with parameters $\min =0.06$ and $\max =0.12$ corresponding to the observations made at Biarritz Grande Plage. Then, the subsequent run-up is computed with $H_{S}$ and $T_{p}$ from the date of the former run-up maximum of each event. Results are plotted in the right panel of Figure 12.

This Figure illustrates the variability of results with the slope parameter. For instance, the level 2 events cover a much larger range in terms of run-up (from 4 to $8 \mathrm{~m}$ ) if we consider the three samples with varying slopes compared to the average solution (from 5 to $6.5 \mathrm{~m}$ ). Nevertheless, event taking into account the slope variation, it seems that a damage rule could still be defined in this case although likely less accurately. According to this, the slope parameter is supposed to play an important role also in the RP calculation for any type of rules even those not using explicitly the slope. Finally, we remark that this argument can be used reversely by observing that 


\begin{tabular}{|cccccc|}
\hline Date & Name & Damages & Flux & Level & RP \\
\hline $06 / 01 / 2014$ & Hercules & 2 & 597.78 & 4.82 & 101.09 \\
$21 / 01 / 1965$ & & & 584.99 & 4.79 & 52.71 \\
$02 / 02 / 2014$ & Nadja & 2 & 480.64 & 4.87 & 14.44 \\
$04 / 03 / 2014$ & Christine & 2 & 500.52 & 4.79 & 9.10 \\
$11 / 03 / 2008$ & & & 494.20 & 4.78 & 7.76 \\
$29 / 12 / 1951$ & 1 & 2 & 539.15 & 4.59 & 5.69 \\
$09 / 11 / 2010$ & 20 & 2 & 435.66 & 4.79 & 4.13 \\
$16 / 02 / 2011$ & Quirin & 0 & 504.96 & 4.65 & 4.08 \\
$13 / 03 / 1976$ & & & 412.96 & 4.73 & 2.12 \\
$06 / 03 / 1959$ & & & 547.74 & 4.15 & 1.58 \\
$10 / 12 / 2007$ & & & 539.49 & 4.10 & 1.20 \\
$21 / 01 / 1971$ & & & 426.34 & 4.56 & 0.99 \\
$08 / 02 / 1996$ & 13 & 0 & 476.93 & 4.38 & 0.92 \\
$30 / 01 / 1990$ & 12 & 1 & 467.62 & 4.41 & 0.89 \\
$30 / 12 / 1998$ & 14 & 1 & 436.81 & 4.50 & 0.88 \\
$25 / 12 / 1965$ & & & 496.37 & 4.25 & 0.82 \\
$13 / 12 / 1978$ & & & 467.78 & 4.37 & 0.81 \\
$26 / 02 / 1989$ & 11 & 0 & 465.42 & 4.33 & 0.67 \\
$06 / 02 / 1950$ & & & 416.72 & 4.47 & 0.61 \\
$05 / 02 / 2014$ & & & 455.31 & 4.30 & 0.54 \\
$13 / 12 / 1982$ & & & 481.06 & 4.10 & 0.46 \\
$13 / 02 / 1979$ & & & 403.58 & 4.42 & 0.45 \\
$03 / 02 / 1961$ & & & 416.04 & 4.17 & 0.25 \\
$13 / 01 / 1951$ & & & 434.37 & 4.07 & 0.24 \\
$02 / 01 / 1986$ & & & 441.10 & 4.02 & 0.24 \\
$02 / 12 / 1976$ & & & 425.57 & 4.11 & 0.24 \\
$30 / 01 / 1988$ & 10 & 0 & 403.46 & 4.16 & 0.21 \\
\hline
\end{tabular}

Table 6. List of storms ranked by decreasing RP based on rules R3. In pink, events not reported in the damage database (Table 1)

the RP of storm Johanna falls to 2.73 years (instead of 17.82 years with the average slope) when taking the weakest value for the slope parameter with $\mathbf{R 5}$.

\section{Conclusions}

In this paper, we compared a database of source variables gathering waves and water level hindcast and observation data and a storm impact database obtained by investigations in archives and local newspapers, a site dominated by waves and tides on the French Basque coast over a period of 65 years to find statistical rules explaining damages. The rules were then verified by applying them on the wave and water level dataset. Finally, the best rules were then used to calculate the events RP. The following conclusions can be drawn from this work :

- On rules : rules based on a wave related parameter (wave height, period, wave energy flux) and water level or equivalently on a response variable combining waves and water level are generally relevant to discriminate storm with and without significant impact at the coast provided they use variable maxima over storm duration. Rules based on mean variable over storm duration were also found to be practically usable but less effi- cient than the former. Rules based on accumulated or integral variables (over storm duration) were not found to explain storm generated damages. Similarly, rules based independently on waves or water level (i.e., considered separately) are not relevant to explain damages as both variables have to be extreme during the storm for damages at the coast to occur,

- On events definition : when applied blind on the wave and water level database, except for the rules involving wave period as a parameter, all the rules were overall able to automatically detect storms inducing damages as identified in the historical investigations without detecting too many false positives. The best rule was the one based on wave energy flux (or equivalently the significant wave height) and water level maxima over the event.

- On return periods (RP) : the best damage rules, identified at the validation stage, also gives the most consistent result for the values of RP. The method presented in this study was therefore able to establish a link between damages and RP. Nevertheless, the discrepancy observed on storm RP considering the three rules show 


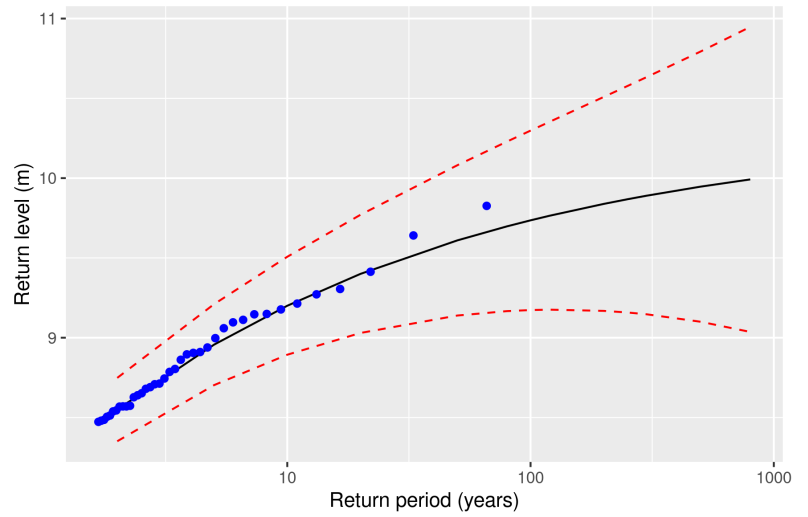

Figure 11. Extrapolation plot for the GPD computed with the time series $\eta+R_{2} \%$ (rule $\mathbf{R 5}$ ) for a threshold of $7.26 m$. The lines correspond to the model and its $95 \%$ confidence interval, the black dots correspond to the empirical values from the time series.
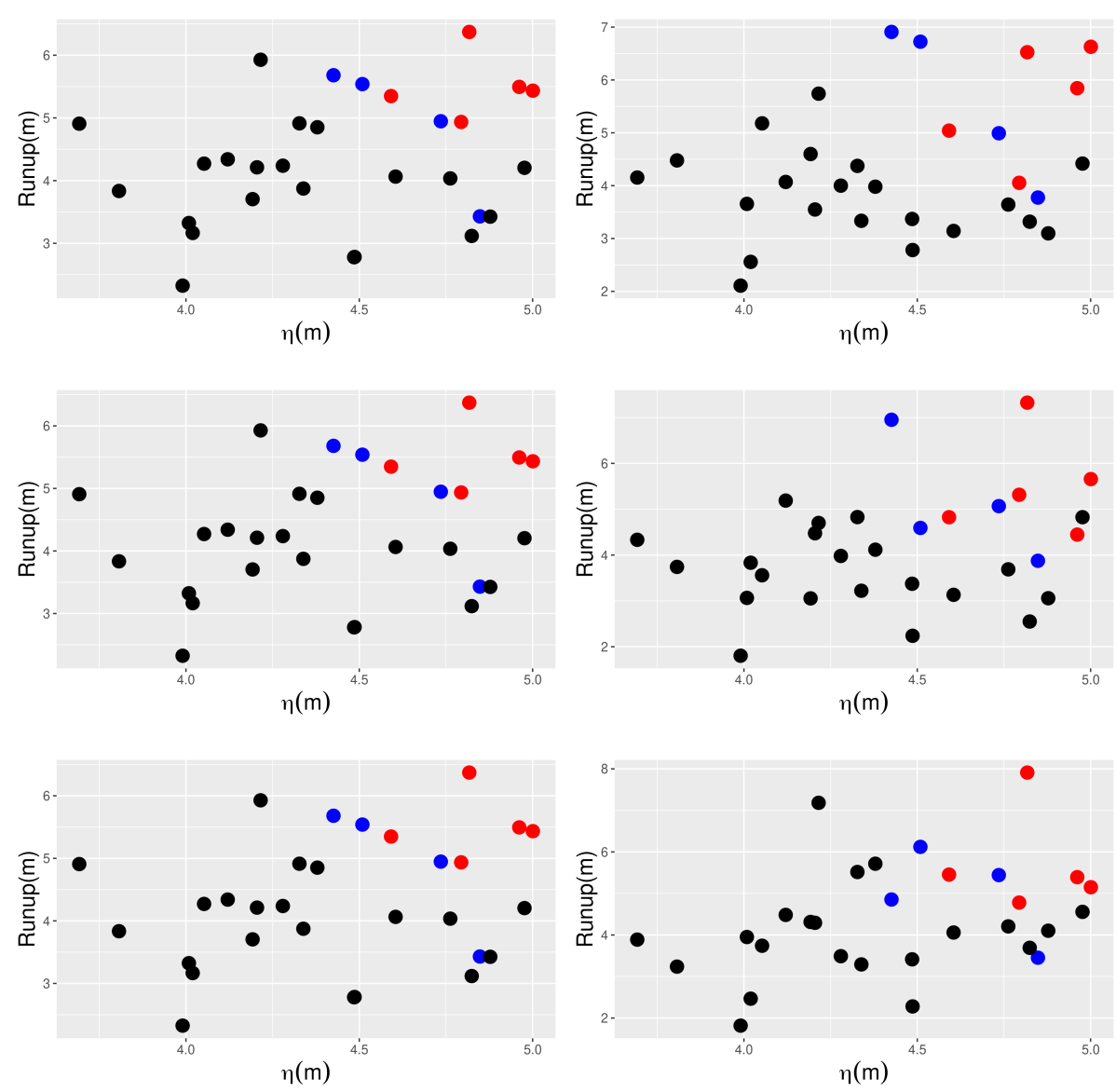

Figure 12. Maxima of the Run-up $R_{2} \%$ versus maxima of water level $\eta$ during historical events. The left plots corresponds to values computed with a constant beach slope $\beta=0.09$ (similar to Figure 7 without applying distribution correction). The right plots are obtained by computing the Run-up maximum run-up $R_{2} \%$ by sampling one random beach slope for each event from a uniform distribution (with parameters $\min =0.06$ and $\max =0.12$ ). Each line corresponds to a different set of random slopes used to compute the run-up on the right panel. 
that there is still work to be done to compute accurate and meaning-full RP really traducing flood damage intensity.

\section{Acknowledgments}

The authors of this paper acknowledge financial support from the European POCTEFA program MAREA EFA046/15 and MARLIT EFA344/19, the "extreme events" AST OASU and the initial funding source from the university of Pau and Pays Adour through the API program. Financial support from UPPA and CD64 for the PhD fellowship of Florian Arnoux is gratefully acknowledged. Finally, the authors would like to thank Puertos del Estado AZTI Tecnalia and IFREMER for providing access to some of the data used in this analysis.

\section{Authors contribution}

Florian Arnoux : Investigation, Software, Validation, Data Curation, Writing - Original Draft, Writing - Review Editing. Stéphane Abadie : Conceptualization, Investigation, Supervision, Resources, Project administration, Funding acquisition, Writing - Original Draft, Writing - Review Editing. Xavier Bertin : Software, Resources, Writing - Review Editing. Ivan Kojadinovic : Investigation, Supervision, Funding acquisition, Formal analysis, Software, Validation, Writing Original Draft, Writing - Review Editing.

\section{References}

[1] C. Small, R. J. Nicholls, A global analysis of human settlement in coastal zones, Journal of Coastal Research (2003) 584-599.

[2] R. J. Nicholls, F. M. Hoozemans, M. Marchand, Increasing flood risk and wetland losses due to global sea-level rise: regional and global analyses, Global Environmental Change 9 (1999) S69-S87.

[3] A. Van Dongeren, P. Ciavola, G. Martinez, C. Viavattene, T. Bogaard, O. Ferreira, R. Higgins, R. McCall, Introduction to risc-kit: Resilience-increasing strategies for coasts, Coastal Engineering 134 (2018) 2-9.

[4] P. Bernardara, F. Mazas, X. Kergadallan, L. Hamm, A two-step framework for over-threshold modelling of environmental extremes, Natural Hazards and Earth System Sciences 14 (3) (2014) 635.

[5] F. Mazas, L. Hamm, An event-based approach for extreme joint probabilities of waves and sea levels, Coastal Engineering 122 (2017) 44-59.

[6] F. Mazas, Extreme events: a framework for assessing natural hazards, Natural Hazards 98 (3) (2019) 823-848.

[7] T. Wahl, N. G. Plant, J. W. Long, Probabilistic assessment of erosion and flooding risk in the northern gulf of mexico,
Journal of Geophysical Research: Oceans 121 (5) (2016) 3029-3043.

[8] B. Gouldby, F. Méndez, Y. Guanche, A. Rueda, R. Mínguez, A methodology for deriving extreme nearshore sea conditions for structural design and flood risk analysis, Coastal Engineering 88 (2014) 15-26.

[9] F. Li, P. Van Gelder, R. Ranasinghe, D. Callaghan, R. Jongejan, Probabilistic modelling of extreme storms along the dutch coast, Coastal Engineering 86 (2014) $1-13$.

[10] Y. Zong, M. J. Tooley, A historical record of coastal floods in britain: frequencies and associated storm tracks, Natural hazards 29 (1) (2003) 13-36.

[11] J.-F. Breilh, X. Bertin, É. Chaumillon, N. Giloy, T. Sauzeau, How frequent is storm-induced flooding in the central part of the bay of biscay?, Global and Planetary change 122 (2014) 161-175.

[12] I. D. Haigh, O. Ozsoy, M. P. Wadey, R. J. Nicholls, S. L. Gallop, T. Wahl, J. M. Brown, An improved database of coastal flooding in the united kingdom from 1915 to 2016, Scientific data 4 (2017) 170100.

${ }^{[13]}$ E. Garnier, P. Ciavola, T. Spencer, O. Ferreira, C. Armaroli, A. McIvor, Historical analysis of storm events: case studies in france, england, portugal and italy, Coastal Engineering 134 (2018) 10-23.

[14] N. Giloy, Y. Hamdi, L. Bardet, E. Garnier, C.-M. Duluc, Quantifying historic skew surges: an example for the dunkirk area, france, Natural Hazards 98 (3) (2019) 869893.

[15] D. Idier, J. Rohmer, R. Pedreros, S. Le Roy, J. Lambert, J. Louisor, G. Le Cozannet, E. Le Cornec, Coastal flood: a composite method for past events characterisation providing insights in past, present and future hazards-joining historical, statistical and modelling approaches, Natural Hazards 101 (2) (2020) 465-501.

[16] N. Giloy, C.-M. Duluc, R. Frau, Y. Ferret, T. Bulteau, F. Mazas, T. Sauzeau, La base de données tempetes: un support pour une expertise collégiale et interdisciplinaire des informations historiques de tempêtes et de submersions, in: XVèmes Journées Nationales Génie CôtierGénie Civil, 2018.

[17] D. Morichon, I. De Santiago, M. Delpey, T. Somdecoste, A. Callens, B. Liquet, P. Liria, P. Arnould, Assessment of flooding hazards at an engineered beach during extreme events: Biarritz, sw france, Journal of Coastal Research 85 (sp1) (2018) 801-805.

[18] M. Beauvivre, 50 ans de tempêtes sur le littoral basque, Tech. rep., Université de Pau et des Pays de l'Adour (2016). 
[19] E. Egurrola, Les tempêtes et les phénomènes de submersion sur la côte basque, Tech. rep., Université de Bretagne Occidentale (2017).

[20] S. Abadie, M. Beauvivre, E. Egurrola, C. Bouisset, I. Degremont, F. Arnoux, A database of recent historical storm impact on the french basque coast, Journal of Coastal Research 85 (sp1) (2018) 721-725.

[21] F. Arnoux, S. Abadie, X. Bertin, I. Kojadinovic, A database to study storm impact statistics along the basque coast, Journal of Coastal Research 85 (sp1) (2018) 806810.

[22] Y. Zhang, A. M. Baptista, Selfe: a semi-implicit eulerianlagrangian finite-element model for cross-scale ocean circulation, Ocean modelling 21 (3-4) (2008) 71-96.

[23] A. Roland, Development of $\{$ WWM II $\}$ : Spectral wave modelling on unstructured meshes (2008).

[24] X. Bertin, K. Li, A. Roland, J.-R. Bidlot, The contribution of short-waves in storm surges: Two case studies in the bay of biscay, Continental Shelf Research 96 (2015) 115.

[25] E. Kalnay, M. Kanamitsu, R. Kistler, W. Collins, D. Deaven, L. Gandin, M. Iredell, S. Saha, G. White, J. Woollen, et al., The ncep/ncar 40-year reanalysis project, Bulletin of the American meteorological Society 77 (3) (1996) 437-472.

[26] H. F. Stockdon, R. A. Holman, P. A. Howd, A. H. Sallenger, Empirical parameterization of setup, swash, and runup, Coastal engineering 53 (7) (2006) 573-588.

[27] D. Chanu, Étude vidéo de la submersion d'une plage en fond de baie, Tech. rep., ISABTP, Université de Pau et des Pays de l'Adour (2019).

[28] R. C. Team, et al., R: A language and environment for statistical computing (2013).

[29] CETMEF, Analyse statistique des niveaux d'eau extrêmes - environnements maritimes et estuariens, Tech. rep. (2013).

[30] L. Breiman, J. Friedman, R. Olshen, C. Stone, Classification and Regression Trees, Wadsworth, 1984.

[31] S. Coles, An introduction to statistical modeling of extreme values, London, United Kingdom: Springer-Verlag, 2001.

[32] P. Thompson, Y. Cai, D. Reeve, J. Stander, Automated threshold selection methods for extreme wave analysis, Coastal Engineering 56 (10) (2009) 1013

- 1021. doi:https://doi.org/10.1016/j. coastaleng.2009.06.003.

URL http://wwW.sciencedirect.com/ science/article/pii/s0378383909000921
[33] J. Benavente, L. Del Río, F. J. Gracia, J. A. Martínezdel Pozo, Coastal flooding hazard related to storms and coastal evolution in valdelagrana spit (cadiz bay natural park, sw spain), Continental Shelf Research 26 (9) (2006) 1061-1076.

[34] C. Armaroli, E. Duo, Validation of the coastal storm risk assessment framework along the emilia-romagna coast, Coastal Engineering 134 (2018) 159-167.

[35] S. Leroy, R. Pedreros, C. André, F. Paris, S. Lecacheux, F. Marche, C. Vinchon, Coastal flooding of urban areas by overtopping: dynamic modelling application to the johanna storm (2008) in gâvres (france), Natural Hazards and Earth System Science 15 (11) (2015) 2497-2510.

[36] F. Serinaldi, Dismissing return periods!, Stochastic Environmental Research and Risk Assessment 29 (4) (2015) 1179-1189. 